\title{
Microstructure development and autogenous shrinkage of mortars with C-S-H seeding and internal curing
}

Mateusz Wyrzykowski ${ }^{1}$, Alexander Assmann ${ }^{2}$, Christoph Hesse $^{2}$, Pietro Lura ${ }^{1,3}$

1 Empa, Swiss Federal Laboratories for Materials Science and Technology, Switzerland

2 BASF Construction Additives GmbH, Trostberg, Germany

3 Institute for Building Materials, ETH Zurich, Switzerland

Corresponding author: mateusz.wyrzykowski@empa.ch, Tel. +41 587654541

\begin{abstract}
The impact of a hardening accelerator based on C-S-H seeding on the microstructure development and the autogenous shrinkage of low water-to-cement ratio (w/c) mortars is studied. C-S-H seeding leads to a significant refinement of the pore structure at early stages of hydration. In the w/c 0.35 mortar with C-S-H seeding, higher mechanical properties are measured up to $1 \mathrm{~d}$; later the effect of seeding becomes insignificant. On the other hand, in the w/c 0.30 mortar the mechanical properties at later ages were reduced with $\mathrm{C}-\mathrm{S}-\mathrm{H}$ seeding. At the same time, the faster refinement of porosity due to seeding at very early ages leads to faster self-desiccation in all mortars. Consequently, lower RH is reached, which is accompanied by higher autogenous shrinkage of the mortars with C-S-H seeding. As a countermeasure, superabsorbent polymers (SAP) were This document is the accepted manuscript version of the following article: Wyrzykowski, M., Assmann, A., Hesse, C., \& Lura, P. (2020). Microstructure development and autogenous shrinkage of mortars with $\mathrm{C}-\mathrm{S}-\mathrm{H}$ seeding and internal curing. Cement and Concrete Research, 129, 105967 (12 pp.). https://doi.org/10.1016/j.cemconres .2019.105967


employed as internal curing agents to reduce self-desiccation and autogenous shrinkage in mortars with seeding agents.

\section{Introduction}

Accelerated hydration and hardening of cement can have practical advantages in various applications. Notable examples are prefabricated elements where fast demolding is necessary, screeds, topping mortars, repair mortars, concretes for which fast processing of the surface is necessary or concretes cast at low temperatures [1-5].

Acceleration of the hardening process of cement-based materials can be obtained in one of the following ways:

- $\quad$ Using fast-reacting cements, e.g. calcium sulfoaluminate (CSA) cements [1];

- Modifying the conditions of curing, e.g. $\mathrm{CO}_{2}$ curing [6], or more commonly, high temperature curing [7-9];

- With additives that act as catalysts of cement hydration. Bentz et al. [4] proposed a classification that distinguishes chemical accelerators (e.g., the commonly used calcium salts $\mathrm{CaCl}_{2}$ or $\mathrm{Ca}\left(\mathrm{NO}_{3}\right)_{2}$ [10]) from physical accelerators (fine fillers, e.g. limestone or quartz powder). The action of the latter is due to providing new nucleation sites for the hydration products and improving the percolation of solids by reducing the interparticle distances [1113], which accelerates the development of the mechanical properties. Further acceleration of hydration can be obtained with fine fillers due to increased sheering during mixing [13]

One method of physical acceleration is the so-called seeding. This method is based on adding hydration products (seeds) at the mixing stage (or to a dry mix) that promote formation of the new 
products. In particular, the hydration of Portland cement and the formation of its main hydration product, calcium silicate hydrate $(\mathrm{C}-\mathrm{S}-\mathrm{H})$ from tricalcium silicate, $\mathrm{C}_{3} \mathrm{~S}$ (the main phase in Portland cement clinker, contributing primarily to the formation of $\mathrm{C}-\mathrm{S}-\mathrm{H})$ can be accelerated by using hydrated C-S-H as seeding agent [14]. Thomas et al. [14] showed that the formation of C-S-H is an autocatalytic process, where the presence of the C-S-H gel stimulates its further formation. The presence of synthetic C-S-H was shown in [15] to accelerate the dissolution of the $\mathrm{C}_{3} \mathrm{~S}$ phase and nucleation of the C-S-H. In [16], C-S-H seeding accelerated the hydration of both ordinary Portland cement paste and alkali-activated blast furnace slag pastes, promoting the nucleation and growth processes. Recently, after achieving efficient dispersion of the synthetic C-S-H, it has become possible to introduce the C-S-H seeding technology into the market of cement-based materials [17].

Even though the seeding technology has been studied in a number of papers, these studies focused on the mechanism of the acceleration of the hydration process and its efficiency, rather than on the early-age performance of the accelerated materials. The need for further studies of the early-age behavior was highlighted in the work by Hubler et al. [16], where the alkali-activated slag pastes with C-S-H seeding had higher strength when cured in sealed conditions, but experienced strength reduction while cured under water. The latter was explained as a result of cracking due to differential strains between the interior of the samples undergoing high autogenous shrinkage due to acceleration and the water-cured surfaces. The main motivation for the present paper is thus gaining understanding of the development of microstructural properties (mainly the porosity), the mechanical properties and the early-age deformations (autogenous shrinkage) in mortars with C-S-H seeding. 
Accepted version. Published as: M. Wyrzykowski, A. Assmann, C. Hesse, P. Lura, Microstructure development and autogenous shrinkage of mortars with C-S-H seeding and internal curing, Cem Concr Res 129 (2020) 105967. https://doi.org/10.1016/j.cemconres.2019.105967

Cement-based materials with low water-to-cement ratio (w/c), usually lower than 0.40 , experience autogenous shrinkage due to consumption of water by the hydrating cement (chemical shrinkage) $[18,19]$. With faster hydration of cement, brought about by the C-S-H seeding, one could expect that the negative effect of autogenous shrinkage, i.e. early-age cracking, may become especially pronounced. With this aspect in mind, our study also focuses on the combination of C-S-H seeding with internal curing by means of superabsorbent polymers (SAP). When SAP are added to low w/c mixtures, they absorb water during mixing and release it at later stage during cement hydration. In this way they can compensate for the chemical shrinkage and reduce self-desiccation, i.e. decrease of the internal relative humidity $(\mathrm{RH})$, and finally autogenous shrinkage, in a process called internal curing [20, 21].

In this study, mortars with w/c of 0.30 and 0.35 , with or without $\mathrm{C}-\mathrm{S}-\mathrm{H}$ seeding and SAP were examined. The mix compositions tested are related to commercially available dry mix mortars like tile adhesives or non-shrink grouts. However, they are simplified compared to the commercial products and consist only of binder and fillers, with a minimum of further additives. The mortar composition was optimized for higher sensitivity regarding shrinkage by reducing the volume of aggregates and decreasing the w/c.

The evolution of cement hydration was followed with isothermal calorimetry. The evolution of the microstructure (by multi-cycle mercury-intrusion porosimetry (MIP) [22]) and of compressive strength was studied until $28 \mathrm{~d}$. Self-desiccation, i.e. the reduction of RH in sealed conditions, was studied with water-activity sensors and the corresponding autogenous shrinkage with the corrugated tubes protocol $[23,24]$. Finally, the absorption of pore fluid by the SAP in the mortar was estimated based on the X-ray microtomography of a mortar soon after mixing (see Appendix). 


\section{Materials and Methods}

\subsection{Materials and mixing}

The mortars were prepared with ordinary Portland cement CEM I 52.5 N "Milke classic", HeidelbergCement AG. Limestone powder (Omyacarb 15 AL, Omya GmbH) with median particle size of $15 \mu \mathrm{m}$ was used as a filler ( $39 \%$ by mass of cement). Quartz sand with particle size $0.3-1$ mm was used as aggregate. Deionized water was used as mixing water. The amount of superplasticizer MasterGlenium ACE 30 (BASF Schweiz AG) was adjusted in all mortars to maintain the flow around $200 \mathrm{~mm}$ as measured with the Hägermann cone after 15 taps of the measuring table (see the spread measurements in Table 1). The superplasticizer MasterGlenium ACE 30 is based on polycarboxylate ethers and has a solid content of $30.0 \pm 1.5 \%$ by mass.

Synthetic C-S-H seeding agent in powder form (HyCon S 3200 F, BASF Construction Additives $\mathrm{GmbH}$ ) was used at a dosage of $2 \%$ by mass of cement. HyCon S $3200 \mathrm{~F}$ provides C-S-H seeding particles which are aggregated in powder with a mean particle size of $40 \mu \mathrm{m}$.

In mortars with SAP, solution-polymerized SAP (development product of BASF Construction Additives $\mathrm{GmbH}$ ). The SAP was a covalently cross-linked modified polyacrylamide. The absorption potential determined based on the tea-bag method with synthetic pore solution [25] was $35 \mathrm{~g} / \mathrm{g}$. The irregular SAP particles had sizes below $200 \mu \mathrm{m}$ and median size $\mathrm{d}_{50}=67 \mu \mathrm{m}$ (determined with laser diffraction).

SAP was added at two dosages: $0.14 \%$ and $0.22 \%$ (by mass of cement). The water absorbed by the SAP at the $0.14 \%$ dosage corresponded to a w/c of 0.05 (for the absorption capacity of $35 \mathrm{~g} / \mathrm{g}$ ). Note that the entrained w/c of 0.05 is close to the theoretical value of 0.054 necessary to eliminate self-desiccation according to Powers' model of hydration, see [20]. A higher amount of the SAP 
$(0.22 \%)$ was tested additionally to explore possible improvements of the internal curing performance. The mortars with SAP had the same total $\mathrm{w} / \mathrm{c}$ as the corresponding reference mortars, i.e. 0.30 and 0.35 . Adding the SAP that absorbed part of the mixing water required increasing the superplasticizer amount to maintain similar workability. On the other hand, the mortars with C-SH seeds had lower amount of superplasticizer than the corresponding mortars without seeding; this is due to the dispersing action of the polymer used for stabilization of the seeds.

Both C-S-H seeding agent and SAP are sensitive to moisture during storage. The powders were stored in plastic hermetic containers to minimize the degradation due to premature hydration or preabsorption of water, respectively. All mix compositions are presented in Table 1.

Each mortar was mixed using a 5-1 Hobart mixer, with the batch volume equal to about 11 . The mixing procedure is presented in Table 2.

The experiments took place at $20 \pm 0.3{ }^{\circ} \mathrm{C}$, except the experiments of early age strength evolution (up to $24 \mathrm{~h}$ ) and setting times that took place at the BASF laboratories at $23 \pm 0.5^{\circ} \mathrm{C}$.

Major part of the experiments was carried out at Empa (self-desiccation, autogenous shrinkage, MIP, X-ray microtomography, compressive strength from $1 \mathrm{~d}$ at $20^{\circ} \mathrm{C}$ ) using a single batch of raw materials. Additionally, early-age measurements (up to $24 \mathrm{~h}$ ) (isothermal calorimetry at $20^{\circ} \mathrm{C}$, Vicat setting times and compressive strength until $1 \mathrm{~d}$ at $23^{\circ} \mathrm{C}$ ) were carried out at the BASF laboratories using different batch of raw materials. The isothermal calorimetry tests confirmed that the two batches of raw materials experienced practically the same evolution of hydration. 
Table 1. Mix compositions (in grams per mixing batch). The numbers next to the name refer to the $w / c$.

\begin{tabular}{|c|c|c|c|c|c|c|c|}
\hline Component/Mortar & REF 0.30 & REF 0.35 & C-S-H 0.30 & C-S-H 0.35 & $\begin{array}{c}\text { C-S- } \\
\text { H+SAP } \\
0.30\end{array}$ & $\begin{array}{c}\text { C-S- } \\
\text { H+SAP } \\
0.35\end{array}$ & $\begin{array}{c}\text { C-S- } \\
\text { H+1.5 } \times \text { SAP } \\
0.35\end{array}$ \\
\hline Cement CEM I 52.5 I & 670 & 670 & 670 & 670 & 670 & 670 & 670 \\
\hline Limestone powder & 260 & 260 & 260 & 260 & 260 & 260 & 260 \\
\hline Water & 196.14 & 231.05 & 197.42 & 232.21 & 196.55 & 230.92 & 225.69 \\
\hline Quartz sand & 1070 & 1070 & 1070 & 1070 & 1070 & 1070 & 1070 \\
\hline Superplasticizer & 6.95 & 4.93 & 5.11 & 3.28 & 8.11 & 5.11 & 12.58 \\
\hline $\begin{array}{l}\text { C-S-H seeding } \\
\text { agent }\end{array}$ & 0 & 0 & 13.4 & 13.4 & 13.4 & 13.4 & 13.4 \\
\hline SAP & 0 & 0 & 0 & 0 & 0.96 & 0.96 & 1.46 \\
\hline $\begin{array}{l}\text { Spread } \\
\text { (Hägermann), mm }\end{array}$ & 230 & 210 & 195 & 215 & 194 & 195 & 225 \\
\hline
\end{tabular}

Table 2. Mixing procedure

\begin{tabular}{ll}
\hline Premix dry components separately & $60 \mathrm{~s}$ \\
Place water and plasticizer and premix by hand & $10 \mathrm{~s}$ \\
Add all dry components & $20 \mathrm{~s}$ \\
Mix at $65 \mathrm{rpm}$ (speed 1) & $120 \mathrm{~s}$ \\
Scrap the bowl with mixing paddle & $30 \mathrm{~s}$ \\
Mix at $65 \mathrm{rpm}$ (speed 1) & $60 \mathrm{~s}$ \\
\hline
\end{tabular}

\subsection{Isothermal calorimetry}

Isothermal calorimetry of the mortars was carried out using a TAM Air calorimeter at $20{ }^{\circ} \mathrm{C}$. Due to the external mixing, the initial measurements were affected by the absence of thermal 
Accepted version. Published as: M. Wyrzykowski, A. Assmann, C. Hesse, P. Lura, Microstructure development and autogenous shrinkage of mortars with C-S-H seeding and internal curing, Cem Concr Res 129 (2020) 105967. https://doi.org/10.1016/j.cemconres.2019.105967

equilibrium during insertion of the mixed sample into the calorimeter. Due to this, the first $0.5 \mathrm{~h}$ of measurements was discarded. The measurements were carried out on single specimens and lasted until $24 \mathrm{~h}$ from mixing. Additionally, the REF 0.35 and C-S-H 0.35 mortars were measured until the age of $7 \mathrm{~d}$ in a separate test (duplicate samples, with the difference in cumulative heat at the end of the test not exceeding $0.5 \%$ ).

\subsection{MIP}

The pore structure development was studied by means of multi-cycle MIP [22] on mortar samples in which cement hydration had been arrested by means of solvent exchange with isopropanol [26] at $10 \mathrm{~h}, 2 \mathrm{~d}$ and $28 \mathrm{~d}$ for the REF 0.35 mortar and $5.75 \mathrm{~h}, 2 \mathrm{~d}$ and $28 \mathrm{~d}$ for the C-S-H 0.35 mortar. The ages of $10 \mathrm{~h}$ and $5.75 \mathrm{~h}$ are the equivalent ages at which similar compressive strength was observed in preliminary tests (not presented here) in mortars with and without seeding, respectively.

Removing of water by means of solvent exchange with isopropanol had two aims, namely to arrest hydration of cement and further to empty the pores from water to allow mercury intrusion. It has been suggested in [26] that the isopropanol method allows to best preserve the microstructure compared to other methods of drying.

Directly after mixing, the mortars were poured into plastic containers with diameter equal to $35 \mathrm{~mm}$ and tightly sealed until the age at which hydration was nominally arrested. All the samples of a given mortar (samples tested at different nominal ages) come from the same mixing batch. At each prescribed age, the cylindrical samples were removed from the container and disks of 1.5$2.0 \mathrm{~mm}$ thickness were cut from the samples using a low-speed, precise diamond saw. The disks were next placed in isopropanol for $72 \mathrm{~h}$, followed by $72 \mathrm{~h}$ drying in an oven at $40{ }^{\circ} \mathrm{C}$. 
Accepted version. Published as: M. Wyrzykowski, A. Assmann, C. Hesse, P. Lura, Microstructure development and autogenous shrinkage of mortars with C-S-H seeding and internal curing, Cem Concr Res 129 (2020) 105967. https://doi.org/10.1016/j.cemconres.2019.105967

Directly after drying, the disc samples were cut with pincers into pieces of about 2-3 mm sizes and about $1 \mathrm{~g}$ of cut pieces per measurement was placed in a glass sample holder. After evacuating the air, the sample holder was first filled with mercury at a pressure of $200 \mathrm{kPa}$ in a low-pressure porosimeter (Pascal 140) and next moved to a high-pressure porosimeter (Pascal 440) where two intrusion-extrusion cycles were performed with a maximum pressure of $200 \mathrm{MPa}$. Two samples for each mortar/age were measured.

During the first intrusion cycle, all pores accessible from the surface were filled. Based on the multi-cycle MIP approach [22], it was assumed that after the first extrusion all ink-bottle pores remained filled with mercury. Thus, during the second intrusion cycle, only the interconnected porosity was resolved. In the evaluation of the equivalent pore sizes, the contact angle of mercury was assumed as equal to $140^{\circ}[27]$.

Bear in mind that the MIP results presented here may be to a certain extent subject to the artifacts of the method, e.g. damage of the microstructure at higher pressure, limitations of the assumed model of porosity and contact angle, and others. These artifacts have been all discussed in the literature, e.g. [28-30]. However, we believe that MIP can be still used to deliver insights on the microstructure, in particular when appropriate interpretation is applied (with the multi-cycle MIP as used here) and when used for comparing different microstructures. Such approach was applied here, where we compared the pore structures in reference mortars and mortars with C-S-H seeding.

\subsection{Self-desiccation}

Directly after mixing, mortars were poured into hermetic plastic containers with internal diameter of $43 \mathrm{~mm}$ and height of $11 \mathrm{~mm}$. The height of the layer of the mortar inside the container was about $7 \mathrm{~mm}$. At the age of 2-9 h (the time was chosen based on visual inspection and corresponded 
Accepted version. Published as: M. Wyrzykowski, A. Assmann, C. Hesse, P. Lura, Microstructure development and autogenous shrinkage of mortars with C-S-H seeding and internal curing, Cem Concr Res 129 (2020) 105967. https://doi.org/10.1016/j.cemconres.2019.105967

to the moment when the shine disappeared from the top surface), the samples were inserted into the hermetic measurement chambers. The initial time offset of the start of the measurement was necessary to avoid condensation of moisture on the sensors that could affect the readings. The internal RH evolution (self-desiccation) was measured using water-activity sensors with nominal trueness of $\pm 0.8 \%$ RH by Rotronic. The plastic container with a sample tightly fits a thermally controlled measuring chamber and the water activity sensors are placed behind the metal mesh filter at a distance of about $7 \mathrm{~mm}$ above the top surface mortar. This means that the volume of air between the sample and the sensor was similar (and smaller) than the actual volume of the samples. Considering that the water content of the mortars was orders of magnitude higher than the water content in the air above the samples, it can be assumed that the former dominates the RH above the sample.

The sensors were calibrated before the measurements using four saturated salt solutions with equilibrium RH in the range 75-98\%RH. Each mortar was measured at 2 or 3 stations in parallel. During the measurements, the temperature of the sensors and the samples was maintained at $20 \pm$ $0.05^{\circ} \mathrm{C}$ by means of a thermostat-controlled water bath with water circulating in the casings of the measuring chambers. The measurements continued until the age of $7 \mathrm{~d}$ and were logged at 1-min time intervals.

\subsection{Autogenous shrinkage}

Autogenous shrinkage was measured using a corrugated-tube protocol based on the ASTM standard [24] and modified to enable automatic measurements according to [23].

Corrugated tubes of diameter $29 \mathrm{~mm}$ and length $420 \mathrm{~mm}$ were placed vertically on a vibrating table with a steel pipe supporting the tubes. The tubes were filled with fresh mortars directly after 
mixing and closed with plastic plugs. Two or three tubes per each mortar were next put on a measuring bench capable of accommodating 6 samples in parallel. The tubes were fixed at one end and the deformations of the opposite end were measured by means of LVDTs.

The measuring bench was placed in a temperature-controlled silicone oil bath in order to maintain constant temperature of the samples and avoid possible drying of the samples through the tubes. The temperature of the bath was maintained at $20.0 \pm 0.1^{\circ} \mathrm{C}$.

The measurements were taken starting at about $30 \mathrm{~min}$ from mixing (water addition). Strains were calculated by referencing the length changes of the samples to the length at the so-called timezero, see Table 3. The standard [24] prescribes the time of final set determined with the Vicat method as the time-zero of the measurements. However, the time of final set occurs earlier than time-zero in the corrugated tubes, due to higher temperature in the bulky Vicat sample compared to the corrugated tubes [23]. Consequently, zeroing the deformations at the Vicat final set leads to an overestimation of the determined shrinkage, since the considered deformations include part of the large deformations that occur before actual set in the tubes. Moreover, the determination of setting in the mortars might be further prone to errors due to the presence of aggregates that lead to apparently faster setting. In order to correct for these artifacts, shrinkage was referenced to the length at the time instant at which scatter between the shrinkage rates measured on duplicate or triplicate samples reaches a constant, low level (in stark contrast to the high scatter occurring before that time) [23], with standard deviation from duplicate samples below $0.5 \mu \mathrm{m} / \mathrm{m} / \mathrm{min}$. 
Accepted version. Published as: M. Wyrzykowski, A. Assmann, C. Hesse, P. Lura, Microstructure development and autogenous shrinkage of mortars with C-S-H seeding and internal curing, Cem Concr

Res 129 (2020) 105967. https://doi.org/10.1016/j.cemconres.2019.105967

Table 3. Time-zero determined based on the minimum value of scatter of the strain rate $(<0.5$ $\mu \mathrm{m} / \mathrm{m} / \mathrm{min}$ ) used for referencing the strain curves, see [23].

\begin{tabular}{|c|c|c|c|c|c|c|c|}
\hline Mortar & REF 0.30 & C-S-H 0.30 & REF 0.35 & C-S-H 0.35 & $\begin{array}{c}\text { C-S-H+SAP } \\
0.30\end{array}$ & $\begin{array}{c}\text { C-S-H+SAP } \\
0.35\end{array}$ & $\begin{array}{c}\text { C-S- } \\
\text { H+1.5 } \times \text { SAP } \\
0.35\end{array}$ \\
\hline Time-zero & $60 \mathrm{~min}$ & $140 \mathrm{~min}$ & $140 \mathrm{~min}$ & $100 \mathrm{~min}$ & $\begin{array}{c}\text { not } \\
\text { determined* }\end{array}$ & $100 \mathrm{~min}$ & $150 \mathrm{~min}$ \\
\hline
\end{tabular}

* autogenous shrinkage measurements were not carried out for the C-S-H+SAP 0.30 mortar

\subsection{Mechanical properties}

Compressive strength was determined on $40 \times 40 \times 160 \mathrm{~mm}^{3}$ prisms, based on the method described in EN 196-1.

Two groups of tests were carried out (on two different batches of raw materials):

- evolution of strength at $6 \mathrm{~h}$ and $24 \mathrm{~h}$, at $23{ }^{\circ} \mathrm{C}$ (this temperature was used exceptionally at the BASF laboratories where the tests were carried out). The samples were cast in expanded polystyrene molds and demolded directly before testing. These tests were accompanied by the setting time measurements with Vicat method, using two different masses of the penetrating needles (diameter $1 \mathrm{~mm}$ ): $300 \mathrm{~g}$ (for initial and final set), and $1000 \mathrm{~g}$ (for final set). It should be mentioned that the higher temperature of curing and the material of the molds led to more accelerated hydration evolution than in the other tests.

- evolution of strength at later ages (at $1 \mathrm{~d}, 3 \mathrm{~d}$ and $28 \mathrm{~d}$ ), at $20^{\circ} \mathrm{C}$. The samples were cast in steel molds, demolded at the age of $1 \mathrm{~d}$ and kept sealed with plastic food wrap (a minimum of 6 layers) until the time of each measurement. 
All the molds were filled on a vibrating table during 1 min vibration (shorter than the standard 3 min, due to the high workability of the mortars). For each measurement, 3 replicate specimens were used.

\section{Results}

\subsection{Hydration evolution}

In Fig. 1 and 2, the results of isothermal calorimetry are presented as heat release rate and cumulative heat, respectively.

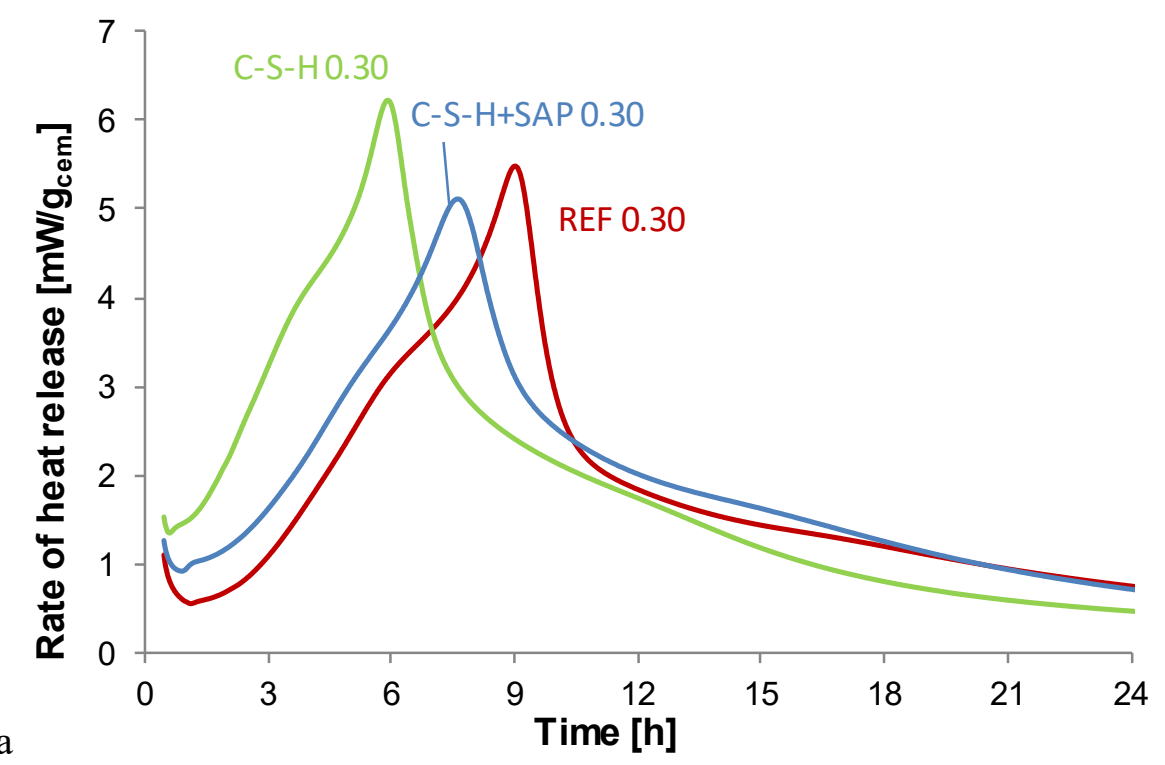




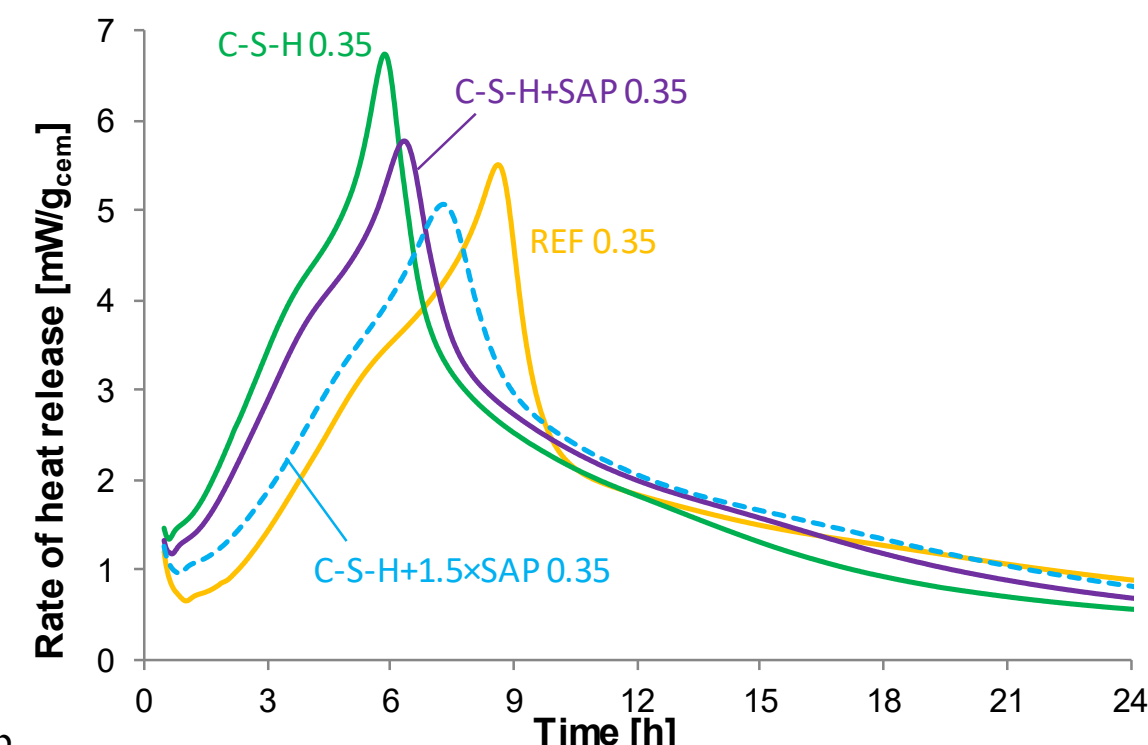

Fig. 1. Results of isothermal calorimetry (rate of heat release) at $20^{\circ} \mathrm{C}$ : a) mortars with $w / c$ $0.30, b)$ mortars with $w / c 0.35$. Results were normalized per mass of cement.

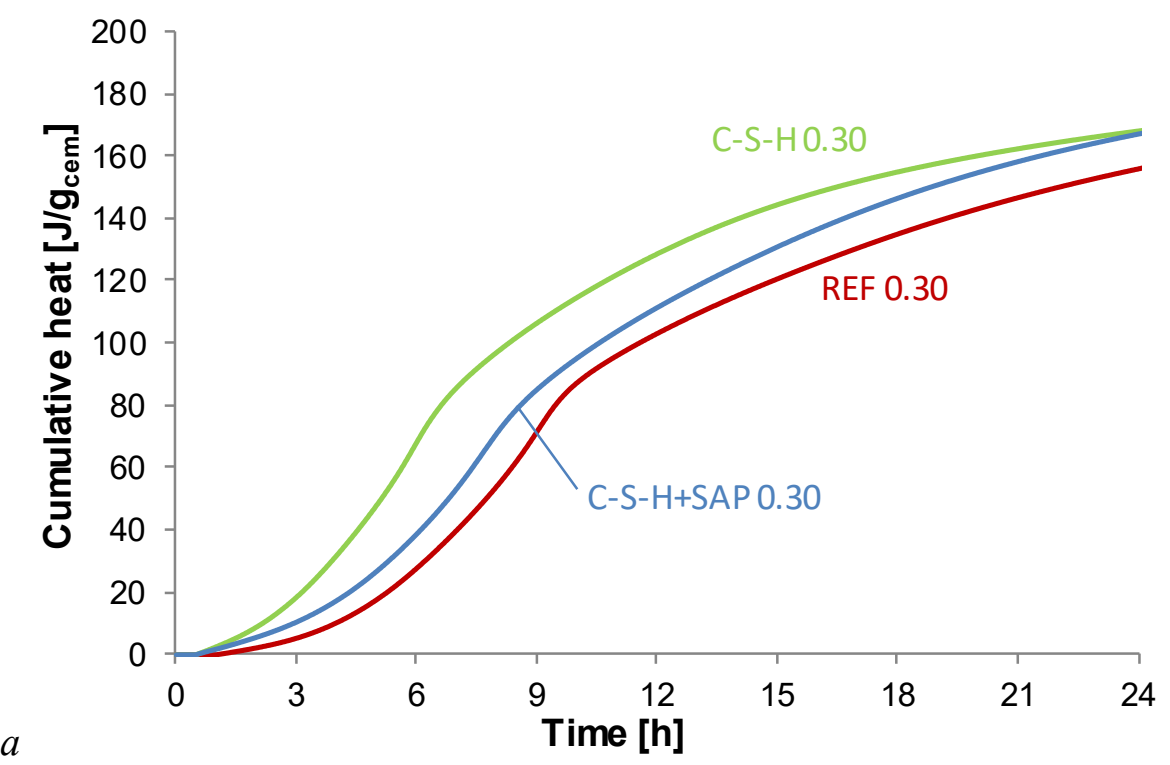



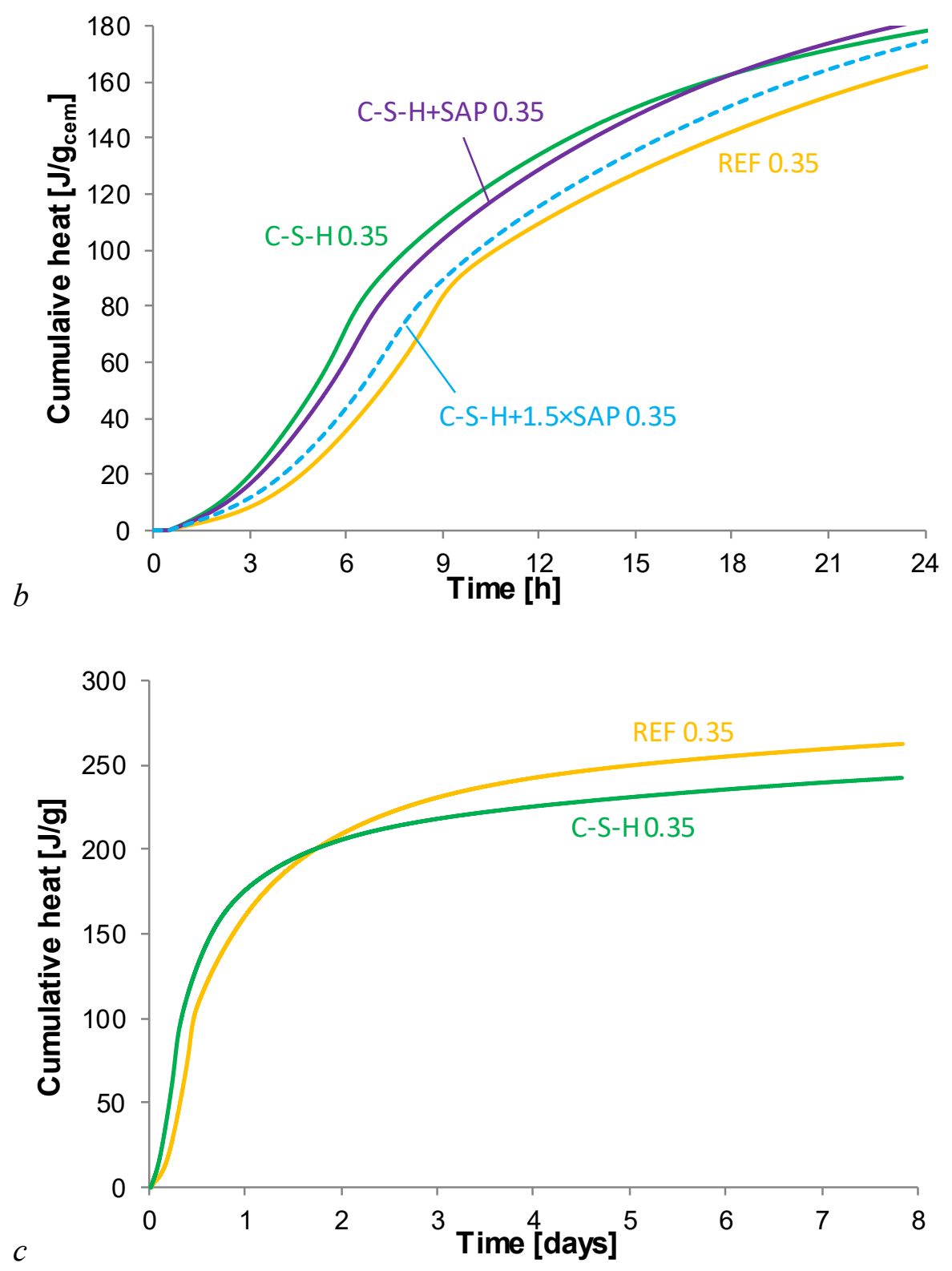

Fig. 2. Results of isothermal calorimetry (cumulative heat) at $20^{\circ} \mathrm{C}$ : a) mortars with $w / c 0.30$, b) mortars with $w / c 0.35, c)$ mortars with $w / c 0.35$ - additional test until 7 d. Results were normalized per mass of cement. 
Accepted version. Published as: M. Wyrzykowski, A. Assmann, C. Hesse, P. Lura, Microstructure development and autogenous shrinkage of mortars with C-S-H seeding and internal curing, Cem Concr Res 129 (2020) 105967. https://doi.org/10.1016/j.cemconres.2019.105967

It needs to be noted that due to external mixing, the first part of the heat evolution curve could not be obtained. The results are considered only from the time of $0.5 \mathrm{~h}$ from mixing start. Due to that, the cumulative hydration heat presented in Fig. 2 is necessarily lower than the actual heat released by the samples.

The results in Fig. 1 clearly show a time shift due to the accelerating effect of C-S-H seeding, for both tested w/c. The main hydration peaks are higher and occur about $3 \mathrm{~h}$ earlier than in the corresponding reference mortars. In the mortars with $\mathrm{C}-\mathrm{S}-\mathrm{H}$ and SAP, the acceleration is less significant (the main hydration peaks of the mortars with C-S-H and SAP occur between those of the mortars with only C-S-H and the corresponding reference mortars, see blue and violet lines in Fig. 1). As seen in Fig. 2c, at later ages the mortars with seeding experience eventually lower heat release compared to the mortars without seeding, due to the hydration rates decreasing fast after the main hydration peak (see Fig. 1).

\subsection{Mercury intrusion porosimetry}

In Fig. 3, the MIP pore size distribution (PSD) curves for the REF 0.35 and C-S-H 0.35 mortars are presented for the three tested ages. The curves from duplicate samples prove that the MIP results had very low scatter.

There was no considerable difference in total MIP-entrained porosity between the two mortars at each considered age (see text inserts in Fig. 3).

As seen in Fig. 3a, at the nominal age of $10 \mathrm{~h}$ (for the REF 0.35 mortar) and $5.75 \mathrm{~h}$ (for the C-S-H 0.35 mortar), even though the two mortars had similar total mercury-accessible porosity, the pore structure was considerably finer in the mortar with C-S-H seeding. The shift in the breakthrough radii (peaks of the differential size distribution curves) from $50 \mathrm{~nm}$ to $30 \mathrm{~nm}$ due to addition of C- 
$\mathrm{S}-\mathrm{H}$ seeding is visible at the earliest tested age both in the first and second intrusion, see Fig. $3 \mathrm{a}$. The first intrusion data reveals the size distribution of the total porosity, while the second intrusion of the interconnected matrix porosity only, see [22].

As can be expected, the total porosity further decreases with time and is approximately the same for both mortars. The effect of pore refinement due to seeding decreases over time - at the age of $2 \mathrm{~d}$, the breakthrough radii for total porosity are about $13 \mathrm{~nm}$ and $12 \mathrm{~nm}$ for the mortars without and with seeding, respectively, while even smaller differences are found for the second intrusion, see Fig. $3 b$ (note that the ordinate axis is presented in logarithmic scale).

At the age of 28 days, there was no considerable difference between the two mortars, regarding both the total porosities and the breakthrough radii, Fig. 3c. A slight difference could be seen only regarding the small shoulder still present in the REF 0.35 mortar for pores of radii $20-50 \mathrm{~nm}$. Since no difference could be seen for the second intrusion (interconnected porosity), this additional part of porosity is probably due to a part of ink-bottle porosity accessible through some entrances larger than the breakthrough radius. 

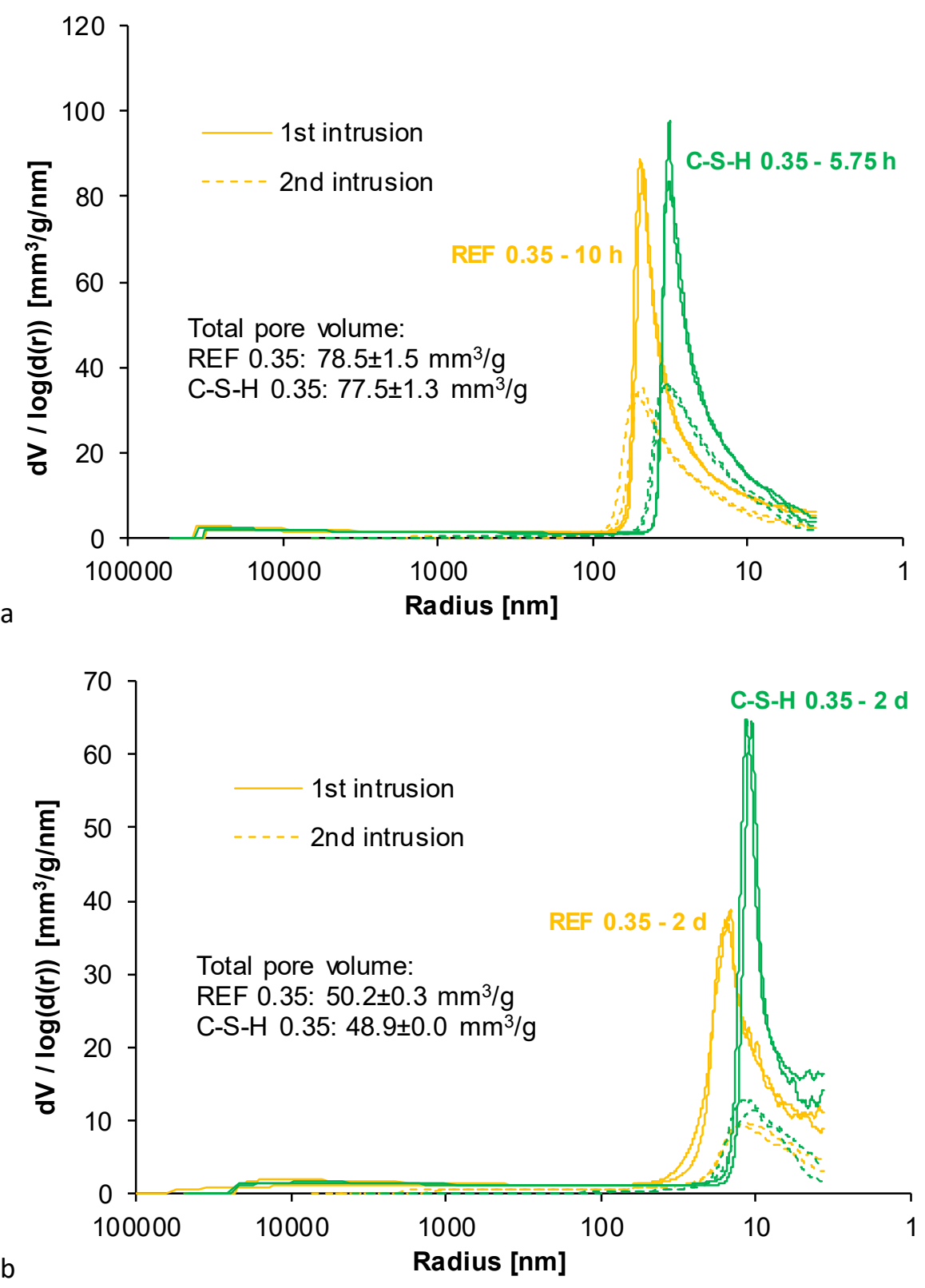


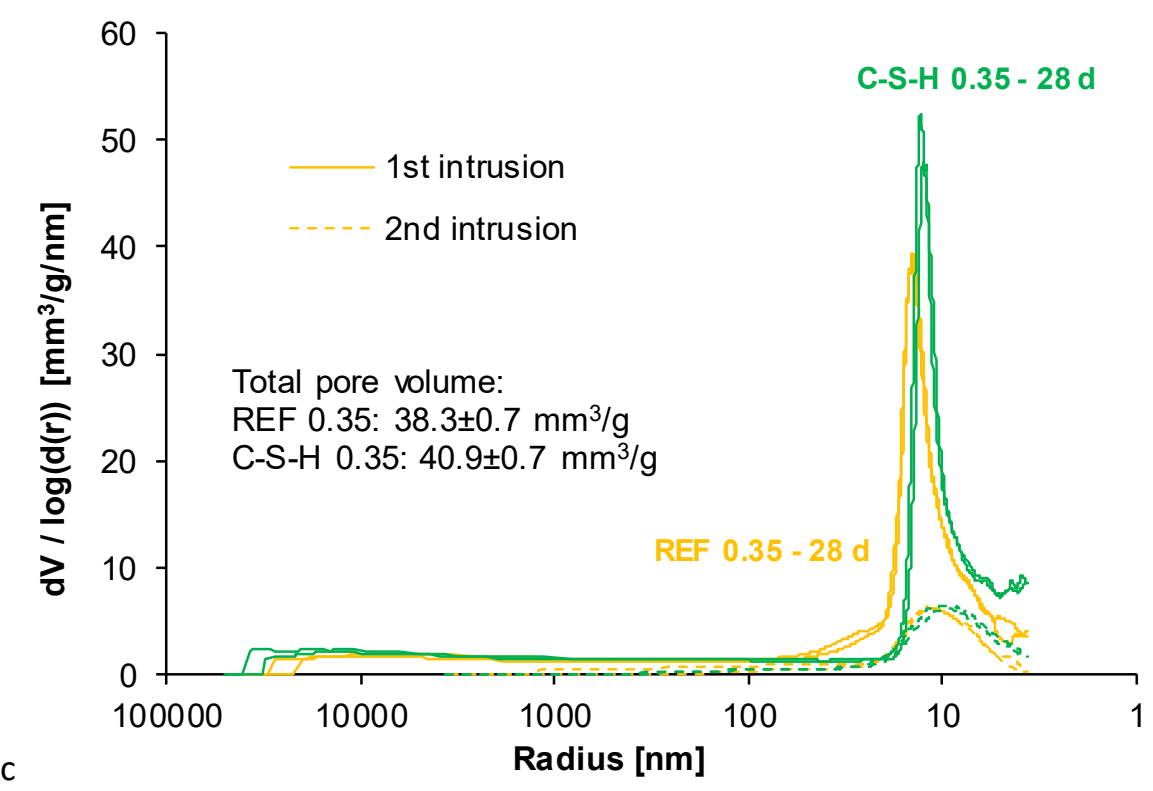

Fig. 3. Multi-cycle MIP results (first and second intrusion, differential size distribution curves) for samples with hydration stopped at different times: a) 5.75/10 h, b) $2 d$, c) $28 d$. Total porosity from the first intrusion is given in the text inserts (average \pm standard deviation from duplicate measurements). Duplicate samples were tested for each mortar (both individual curves for each type of sample are presented).

\subsection{Mechanical properties}

In Table 4, the results of the Vicat setting times measured on samples conditioned at $23{ }^{\circ} \mathrm{C}$ are presented. The acceleration due to C-S-H seeding was observed (both times of final set times and the time window between initial and final set). Similarly as seen in the isothermal calorimetry results, the accelerating effect becomes less significant for the mortars with SAP addition and higher superplasticizer dosage. 
Table 4. Setting times measured with Vicat method (with masses of needles equal to $300 \mathrm{~g}$ and $1000 \mathrm{~g})$ at $23^{\circ} \mathrm{C}$.

\begin{tabular}{|c|c|c|c|c|c|c|c|}
\hline Mortar & REF 0.30 & C-S-H 0.30 & REF 0.35 & C-S-H 0.35 & C-S-H+SAP & $\mathrm{C}-\mathrm{S}-\mathrm{H}+\mathrm{SAP}$ & $\mathrm{C}-\mathrm{S}-\mathrm{H}+1.5 \times \mathrm{SAP}$ \\
\hline & & & & & 0.30 & 0.35 & 0.35 \\
\hline Vicat $300 \mathrm{~g}$ initial & $70 \mathrm{~min}$ & $46 \min$ & $105 \mathrm{~min}$ & $67 \mathrm{~min}$ & $85 \mathrm{~min}$ & $72 \mathrm{~min}$ & $89 \mathrm{~min}$ \\
\hline Vicat $300 \mathrm{~g}$ final & $95 \mathrm{~min}$ & 56 min & $121 \mathrm{~min}$ & $76 \mathrm{~min}$ & 94 min & $82 \mathrm{~min}$ & $94 \mathrm{~min}$ \\
\hline Vicat $1000 \mathrm{~g}$ final & $135 \mathrm{~min}$ & $99 \min$ & $163 \mathrm{~min}$ & $115 \mathrm{~min}$ & $137 \mathrm{~min}$ & $109 \mathrm{~min}$ & $137 \mathrm{~min}$ \\
\hline
\end{tabular}

In Fig 4 and 5, the evolutions of compressive strength measured on samples cured at $23{ }^{\circ} \mathrm{C}$ (at $6 \mathrm{~h}$ and $24 \mathrm{~h}$ ) and $20^{\circ} \mathrm{C}$ (up to $28 \mathrm{~d}$ ) are presented, respectively.

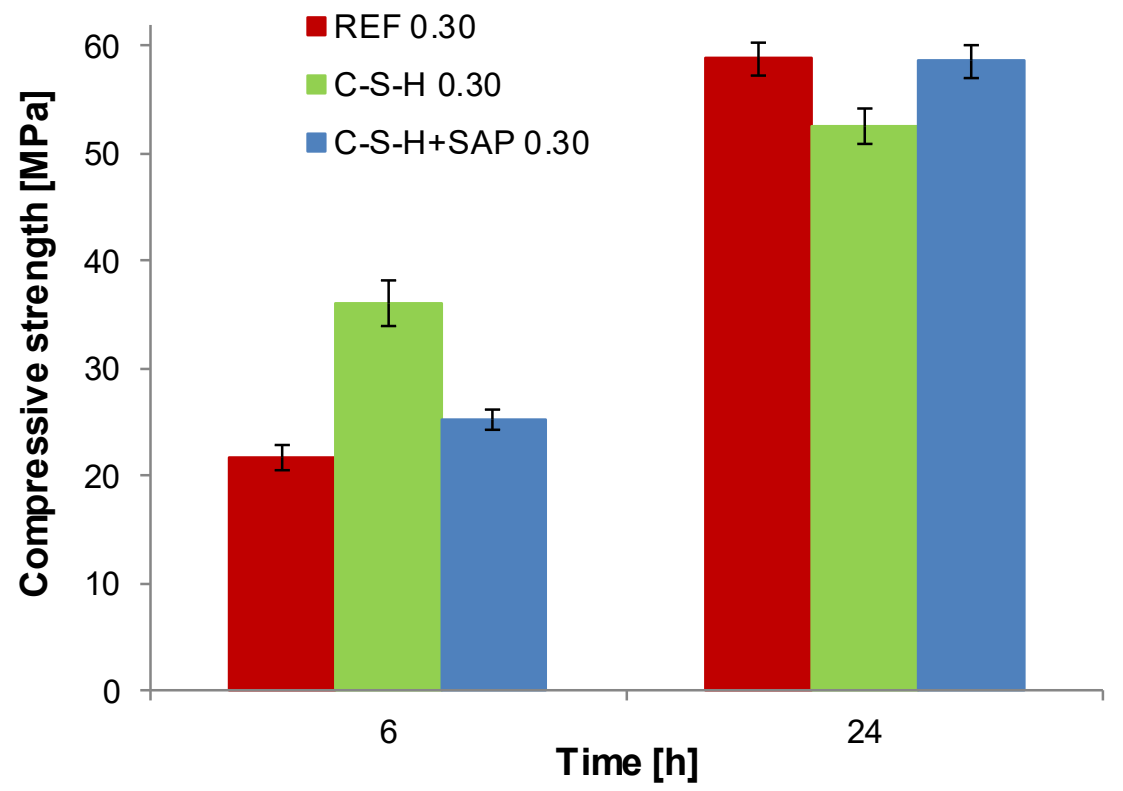




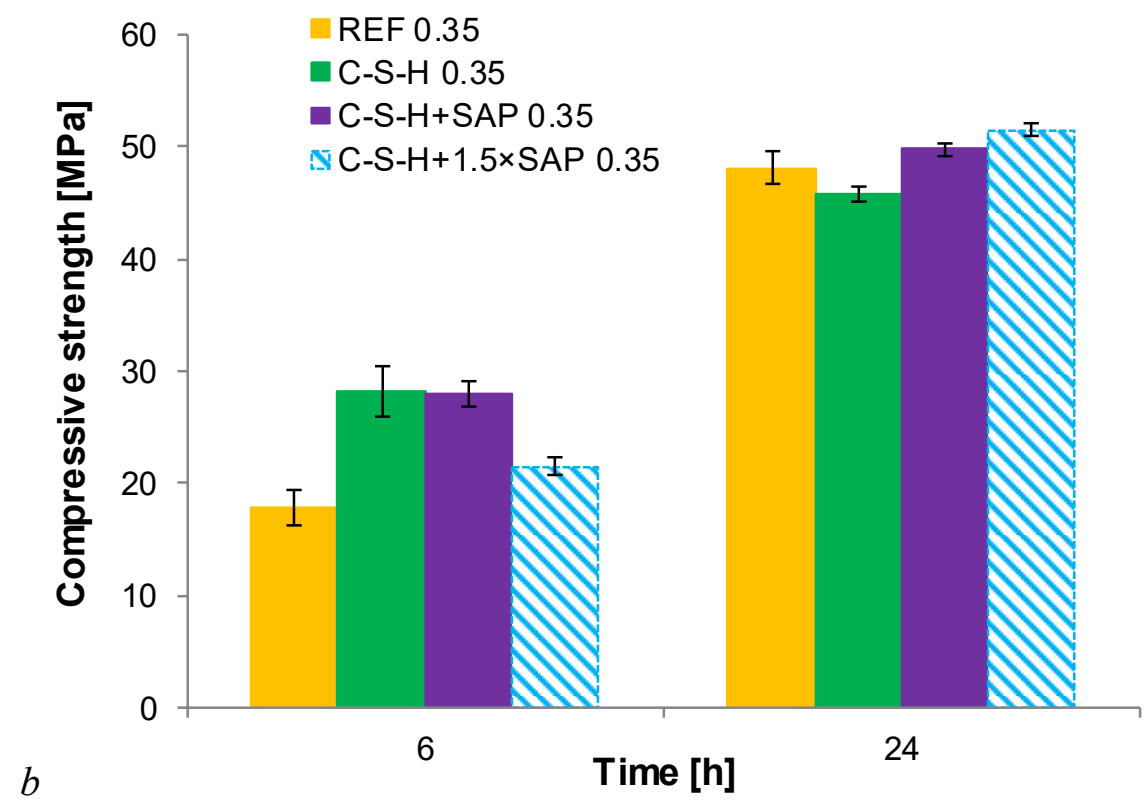

Fig 4. Compressive strength of the mortars at early age: a) mortars with $w / c 0.30, b)$ mortars with $w / c 0.35$. Samples cast in expanded polystyrene molds and cured in sealed conditions at 23 ${ }^{\circ} \mathrm{C}$.

It can be seen in Fig. 4 that C-S-H seeding leads to significantly higher strengths at $6 \mathrm{~h}$ compared to the REF mortars (an increase by almost $60 \%$ was measured for the C-S-H 0.35 and C-S-H+SAP 0.35 mortars). The reduction of strength at the age of $6 \mathrm{~h}$ observed in the mortar with SAP at w/c 0.30 , and for the increased SAP dosage $(1.5 \times)$ at w/c 0.35 is most likely due to a delaying effect of the increased superplasticizer dosage on hydration (necessary for a constant initial flow of the mortar), see e.g. [31, 32]. At $24 \mathrm{~h}$, the accelerating effect of the seeding is no longer visible, and a slight reduction of strength is observed. On the other hand, addition of SAP to the mortars with seeding allows to overcome this effect, and even some promotion of strength compared to the reference mortar is obtained at w/c 0.35 , see Fig. $4 b$. 
In Fig. 5 the results for the mortars conditioned at $20{ }^{\circ} \mathrm{C}$ up to $28 \mathrm{~d}$ are presented. These mortars hydrated slower than those kept at $23{ }^{\circ} \mathrm{C}$ in expanded polystyrene molds, where further temperature increase likely took place resulting in faster hydration. An acceleration is visible at 1 $\mathrm{d}$ for the mortar at w/c 0.35 , Fig. 5b, with a promoting effect of SAP addition, while at later ages no significant effect on strength of the two additives could be observed. On the other hand, for the w/c 0.30 mortar, no effect at $1 \mathrm{~d}$, and reduction of strength at later ages was observed in the mortars with seeding, Fig. 5a.

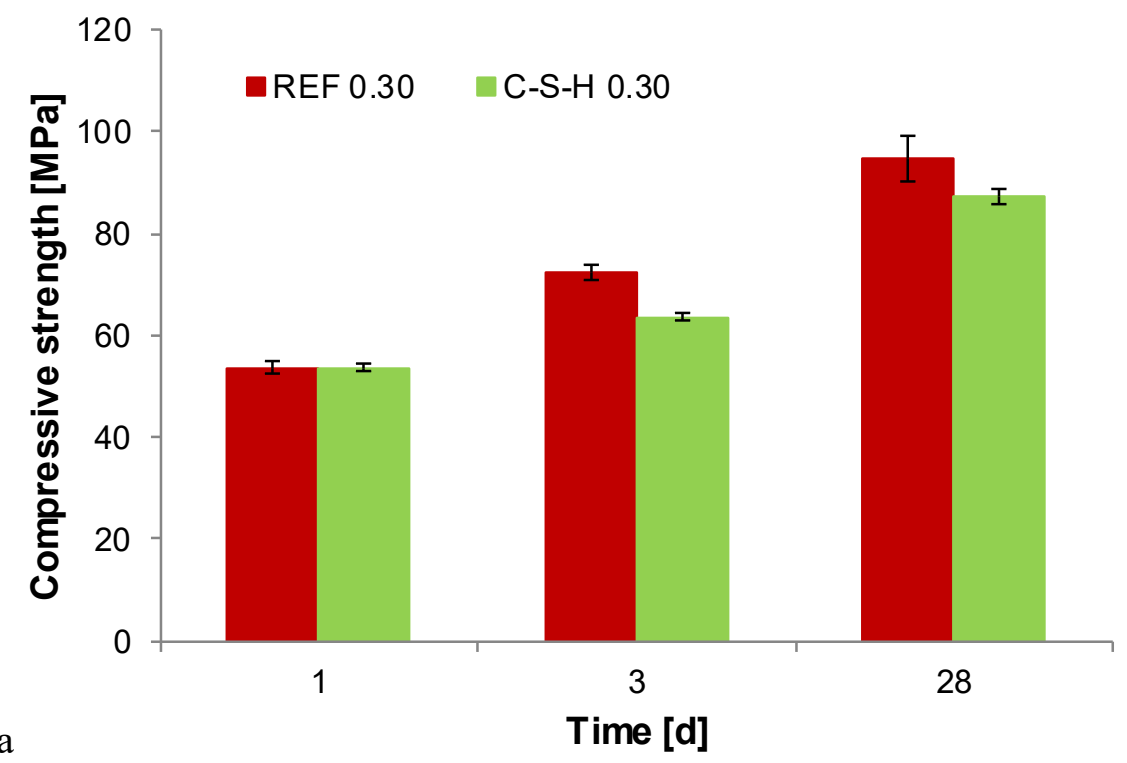




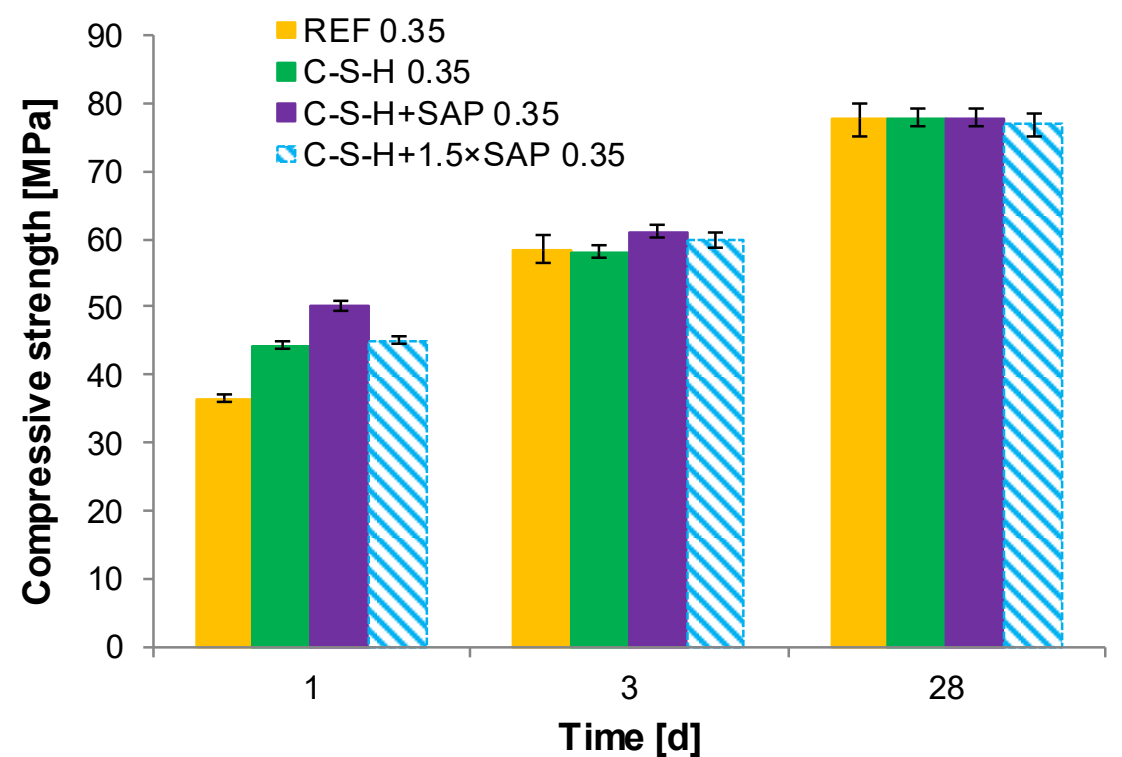

Fig 5. Compressive strength of the mortars cured in sealed conditions $20^{\circ} \mathrm{C}$ : a) mortars with $w / c 0.30, b)$ mortars with $w / c 0.35$.

\subsection{Self-desiccation and autogenous shrinkage}

In Fig. 6, the results of the internal RH measurements are presented, separately for the mortars with w/c 0.30 and w/c 0.35 . It can be seen that the decrease of internal RH (self-desiccation) is initially faster in the mortars with C-S-H seeding. Eventually, lower RH values are reached in the mortars with C-S-H seeding compared to the reference mortars. The self-desiccation was limited by internal curing with SAP, see Fig. 6b. Also, with an increased dosage of SAP (at the same total $\mathrm{w} / \mathrm{c})$, the effect of internal curing in limiting self-desiccation is further enhanced. The increase of RH measured in C-S-H 0.30 mortar by one sensor after about $3 \mathrm{~d}$ is most likely an artifact due to instability of the sensor. 


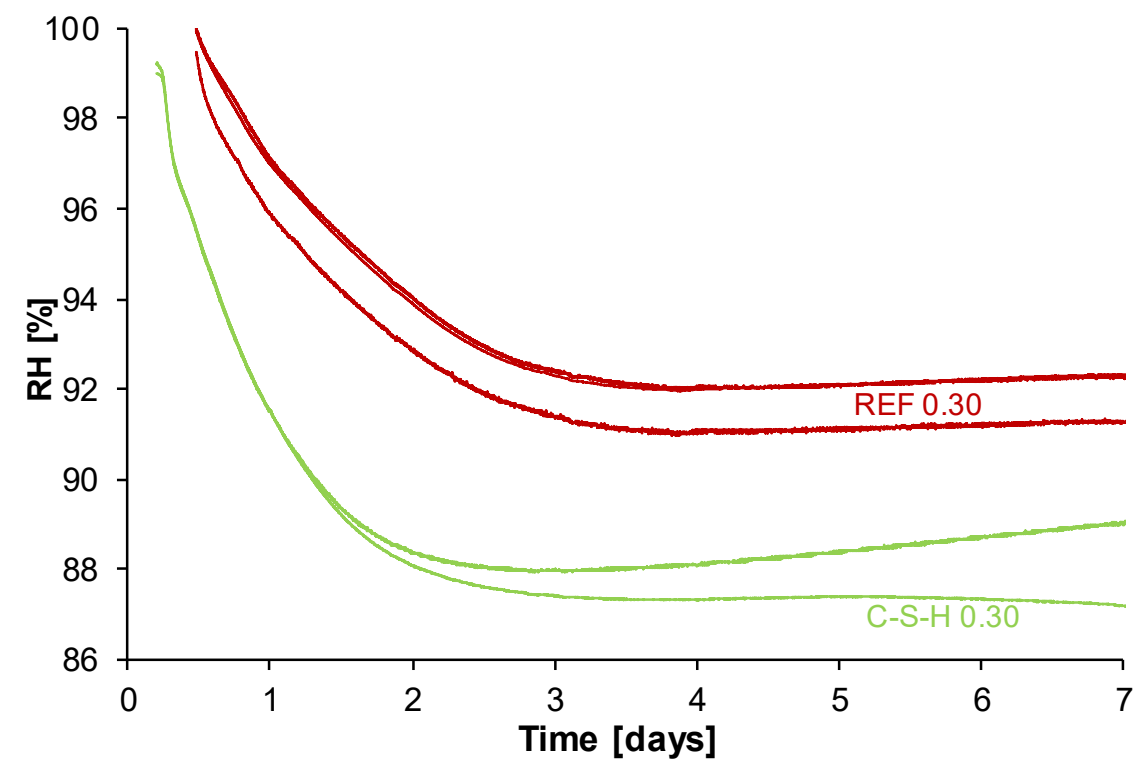

a

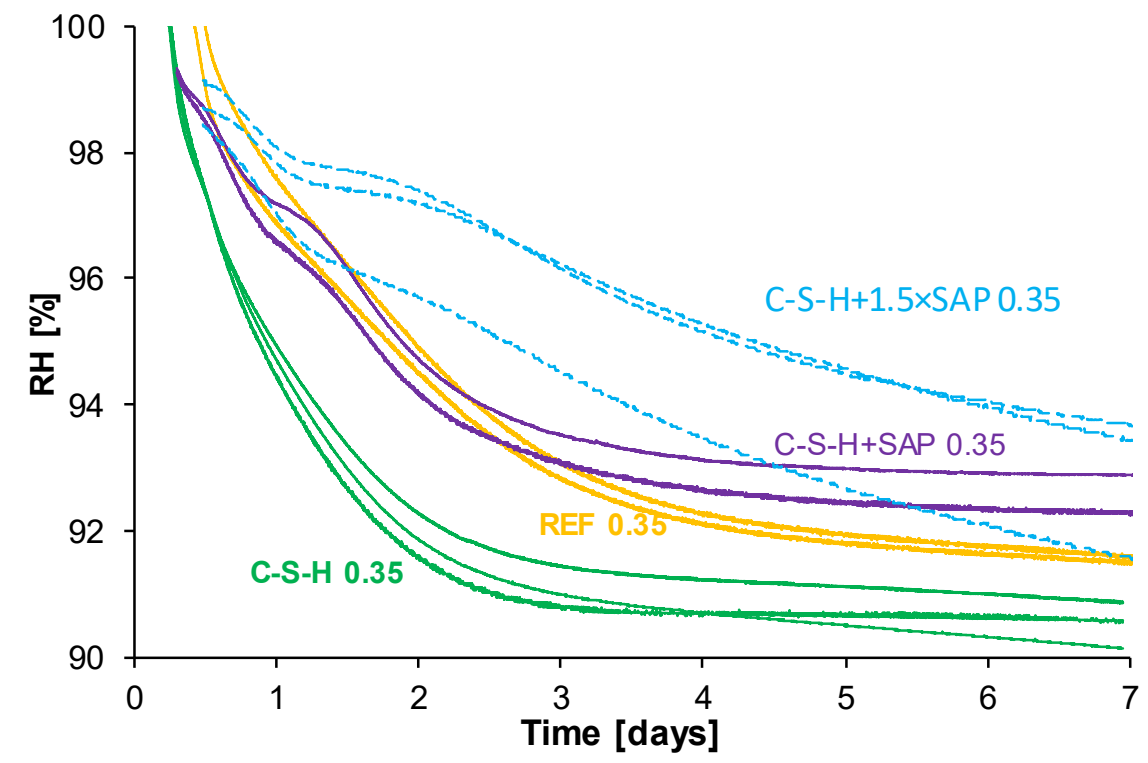

Fig. 6. Internal relative humidity in mortars with a) $w / c 0.30$ and b) $w / c 0.35$. Each curve was measured with a separate sensor (duplicate or triplicate samples).

In Fig. 7, autogenous shrinkage results are presented. The initial steep part of the shrinkage curves occurring in the first few hours after time zero was similar for all the tested mortars and is not 
presented for the sake of better visibility of the later shrinkage behavior (all graphs were cropped at $-600 \mu \mathrm{m} / \mathrm{m})$. The strains are referenced to the length at the time-zero, determined as the time when the scatter in the strain rates between the replicate samples reached a low, stable value [23], see Table 3. Whereas for the mortars with $\mathrm{w} / \mathrm{c} 0.35, \mathrm{C}-\mathrm{S}-\mathrm{H}$ seeding led to faster time-zero (except for the mortar with increased SAP amount, likely due to the higher superplasticizer amount), this was not the case for the w/c 0.30 mortar, see Table 3 .

It should be noted that the initial steep part of the shrinkage curves and the overall magnitude of shrinkage are highly sensitive to the method used for the determination of time-zero. It should be mentioned that the latter parameter can be determined based on different method, e.g. as corresponding to final setting time determined with Vicat method, based on the shape of the shrinkage curves (usually as the knee point in the curve), based on ultrasound measurements, or others [33-35]. In any case, the uncertainty regarding the magnitude of the initial shrinkage part before about $0.5 \mathrm{~d}$ should not have a major impact on the risk of cracking due to restrained shrinkage, thanks to high relaxation at very early ages [36]. On the other hand, the later shrinkage that proceeds after the initial steep increase and continues for the next days should be more important from the point of view of sensitivity to cracking. This later shrinkage shows clear differences between the different mortars. It can be seen that the addition of C-S-H seeding significantly increases the shrinkage rate after about $0.5 \mathrm{~d}$ and the shrinkage proceeds at higher rate until about $3 \mathrm{~d}$.

Mortars with added SAP in addition to C-S-H experienced some moderate swelling stage occurring after the initial steep shrinkage part until the age of about $0.8 \mathrm{~d}$. Later, the shrinkage rate was visibly reduced with internal curing. When the amount of SAP added was increased by $1.5 \times$ (from $0.14 \%$ to $0.22 \%$ by mass of cement), it led to more water absorbed by the SAP and more 
pronounced internal curing effect, leading to further reduction of self-desiccation and almost no autogenous shrinkage between about 0.3 and $3 \mathrm{~d}$, followed by moderate shrinkage afterwards.
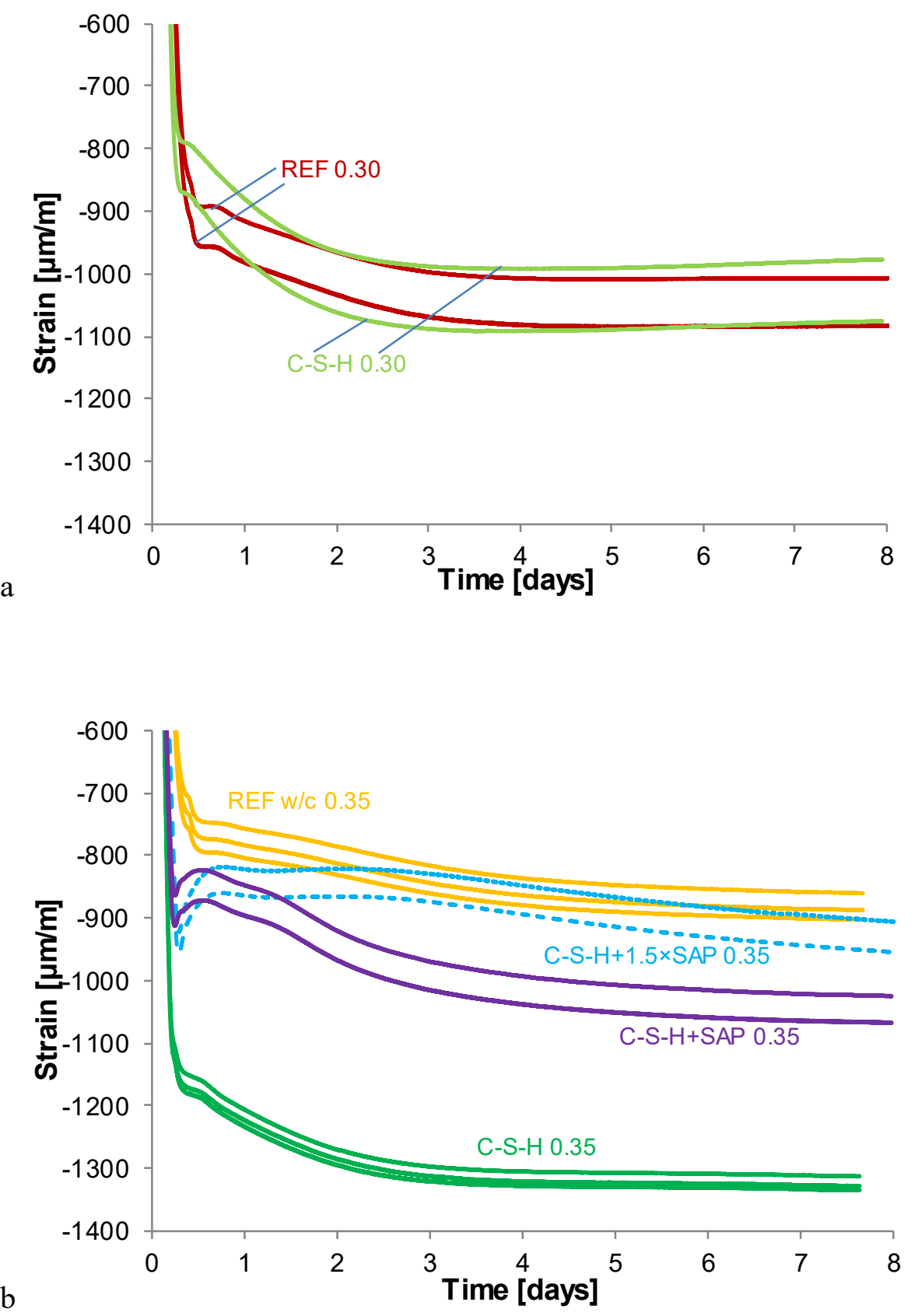
Accepted version. Published as: M. Wyrzykowski, A. Assmann, C. Hesse, P. Lura, Microstructure development and autogenous shrinkage of mortars with C-S-H seeding and internal curing, Cem Concr Res 129 (2020) 105967. https://doi.org/10.1016/j.cemconres.2019.105967

Fig. 7. Autogenous shrinkage in the mortars with a) w/c 0.30 and b) w/c 0.35. Each curve was measured on a separate sample (duplicate or triplicate). The strains are referenced to the length at time zero (see Table 3).

\section{Discussion}

\subsection{Effect of seeding on the microstructure and mechanical properties}

The accelerating effect of C-S-H seeding was confirmed with isothermal calorimetry. The main hydration peak occurred about $3 \mathrm{~h}$ earlier (see Fig. 1) and the induction period was practically eliminated, similarly as in [14]. The acceleration observed with isothermal calorimetry is also in line with shorter setting times observed in the mortars with seeding, see Table 4. However, after the initial acceleration, the mortars with C-S-H seeding experienced lower rates of hydration than the reference mortars soon after the main hydration peak (after about $0.5 \mathrm{~d}$ of hydration). This resulted in lower cumulative hydration heat of the mortar with seeding compared to the reference mortar from the age of about $2 \mathrm{~d}$ observed for the w/c 0.35 mortars. However, it should be stressed that due to external mixing the heat released during the initial 30 min from mixing could not be measured; the heat release in this time was most likely higher for the mortar with seeding, which would reduce the difference in the cumulative heat, see [14]. The inversion effect on cumulative heat of hydration was less significant until $1 \mathrm{~d}$ in the mortars at higher $\mathrm{w} / \mathrm{c}$ of 0.35 . A similar effect of the initial acceleration of hydration followed by ultimately lower degree of hydration, referred to as the temperature inversion, has been observed for high temperature-accelerated hydration of cement phases and cement pastes in [8]. The mechanisms appear to be however different for the two types of acceleration. According to the boundary nucleation model of $\mathrm{C}_{3} \mathrm{~S}$ hydration $[14,37]$, when cement hydration is accelerated by higher temperature, $\mathrm{C}_{3} \mathrm{~S}$ particles are rapidly surrounded 
by hydration products, which prematurely puts an end to the nucleation and growth period of hydration and may ultimately lead to lower hydration degrees. As proposed by Thomas et al. [14] and reported based on qualitative SEM results by Alizadeh et al. [15], in the C-S-H accelerated systems, the faster $\mathrm{C}_{3} \mathrm{~S}$ dissolution initially also led to more $\mathrm{C}-\mathrm{S}-\mathrm{H}$ covering the $\mathrm{C}_{3} \mathrm{~S}$ surfaces compared to the reference system, consequently causing higher rates visible in the heat of hydration measurements. However, such effect was only visible in the initial stage of hydration (first few hours). Later, the hydration products nucleated and grew also on the C-S-H seeds (and hence less of them formed on the $\mathrm{C}_{3} \mathrm{~S}$ surfaces at later ages compared to the reference system). These observations are also in line with the digital simulations of the hydration of $\mathrm{C}_{3} \mathrm{~S}$ with seeding carried out in [14]. Due to the increased fineness of the formed microstructure (better initial space filling) in the system with C-S-H acceleration (see also [14]), the diffusion-controlled kinetics are most likely more affected, resulting in lower hydration rates at later stages of hydration, see Fig. 2c.

In the mortars with SAP, the initial acceleration effect becomes less significant. This is most likely because the mixtures with SAP contained higher amounts of superplasticizer (1.5-3.8 times more compared to the mortars without SAP, see Table 1) which led to a delay of hydration, see e.g. [32] [31], and hence partially reduced the accelerating effect of the C-S-H seeding. Otherwise, for the same amount of plasticizer, and the same w/c, an acceleration of the main hydration peak due to addition of SAP could be expected as SAP absorb part of the mixing water and hence reduce the initial 'basic' w/c (for details see [38]). 
Accepted version. Published as: M. Wyrzykowski, A. Assmann, C. Hesse, P. Lura, Microstructure development and autogenous shrinkage of mortars with C-S-H seeding and internal curing, Cem Concr Res 129 (2020) 105967. https://doi.org/10.1016/j.cemconres.2019.105967

The rates of hydration after the main hydration peak did not drop as significantly in the mortars with C-S-H seeding and SAP, compared to the mortars with only C-S-H seeding. Hence, a smaller inversion effect can be expected for the combination of C-S-H seeding and SAP.

Reduction of porosity before $1 \mathrm{~d}$ occurred faster in the mortar with seeding than in the reference mortar (similar total porosities at 5.75 and $10 \mathrm{~h}$, respectively). However, despite similar total porosities, the mortar with seeding had finer porosity. This is most likely due to better dispersion of the hydration products that form not only on the clinker grains but also on the synthetic C-S-H seeds, hence better filling the original capillary porosity. This observation is in line with the SEM observations in $[14,15]$. There may still exist further differences in smaller pores not accessed by the mercury (note that, for a maximum pressure of $200 \mathrm{MPa}$, the smallest accessible pore was about $3.6 \mathrm{~nm}$ in equivalent radius), likely lower gel porosity in the accelerated mortar. Further, it should be noted that the nominal ages at which the hydration was stopped are necessarily underestimated. After immersing the sample in isopropanol, a certain time is necessary for the solvent to penetrate the pores. According to the estimations in [26], about $3 \mathrm{~h}$ are needed to exchange $50 \%$ of pore water with alcohol in a particle of hardened cement paste of $1 \mathrm{~mm}$ radius (a similar time could be expected for a plate sample with $2 \mathrm{~mm}$ thickness used here). This level of solvent exchange should be sufficient to arrest hydration, because the hydration rate reduces more than three times when the water activity becomes 0.9 and virtually stops when it is below about 0.8 [39]. The differences in porosity become insignificant already at $2 \mathrm{~d}$ of age.

The higher initial hydration rates and the initially refined porosity are in line with higher strength measured at early age in the mortars with C-S-H seeding (at $6 \mathrm{~h}$ for the tests at $23{ }^{\circ} \mathrm{C}$ for both w/c and at $24 \mathrm{~h}$ for the tests at $20^{\circ} \mathrm{C}$ for the w/c 0.35 mortar). At ages beyond $1 \mathrm{~d}$, the effect of seeding on compressive strength was negligible for the w/c 0.35 mortar, which is in line with similar 
porosities and slightly lower (or possibly similar, see the discussion above) hydration degree. A clearly positive effect of SAP addition on strength could be observed for both mortars at $1 \mathrm{~d}$. This means that the lower basic $\mathrm{w} / \mathrm{c}$ in the mortars caused by the absorption of part of the water by SAP, and hence lower capillary porosity and higher strength, overcomes the negative effect of the retardation due to the increased superplasticizer dosage discussed above. Later this effect vanishes and the SAP addition did not have any significant effect on strength at later ages, as shown by the results of the w/c 0.35 mortars.

On the other hand, in the mortar with C-S-H seeding at w/c 0.30 , reduction of strength after $1 \mathrm{~d}$ (and at $23{ }^{\circ} \mathrm{C}$ already at $1 \mathrm{~d}$ ) could be observed, which is in line with the inversion effect of hydration observed in calorimetry. A similar effect of lower strength gain at later ages (in opposition to fast initial strength evolution) was reported by Hubler et al. [16] for Portland cement paste with C-S-H seeding. A possible explanation for the lower mechanical properties at later ages obtained with $\mathrm{C}-\mathrm{S}-\mathrm{H}$ seeding could be due to microcracking caused by autogenous shrinkage (restrained by the aggregates, see [40]) that proceeded at high rates shortly after time-zero. Another possible reason could be due to different morphology of the hydration products formed away from the clinker particles (i.e. on the surfaces of the C-S-H seeds), see [15]. However, no direct evidence is available at this moment.

According to [14], the accelerating action of seeding is due to the following mechanisms: 1) increased number of nucleation sites, reducing the induction period of hydration, 2) higher volume of hydration products growing at the same time in the acceleration period, and 3) formation of hydration products in the pore spaces away from the $\mathrm{C}_{3} \mathrm{~S}$ particles, offsetting the surrounding of the $\mathrm{C}_{3} \mathrm{~S}$ with hydration products that otherwise acts as diffusion barrier. When inert fillers are used, the often-observed accelerated hydration depends on the particular type of filler: reduced 
Accepted version. Published as: M. Wyrzykowski, A. Assmann, C. Hesse, P. Lura, Microstructure development and autogenous shrinkage of mortars with C-S-H seeding and internal curing, Cem Concr Res 129 (2020) 105967. https://doi.org/10.1016/j.cemconres.2019.105967

interparticle distance was found as dominating factor for cement pastes with quartz fillers, while additionally increased nucleation of C-S-H on the limestone grains was reported in [13]. It should be also noted that all the mortars tested here contained fine limestone powder in an amount of $39 \%$ by mass of cement, hence a certain filler effect, likely corresponding to an increased amount of nucleation sites, should be present in all the mortars tested here.

Considering the aforementioned reduced interparticle distance on the other hand, this effect should play a more important role in mixes with higher initial porosity (higher w/c). Indeed, as shown in [41], the efficiency of the filler effect (with limestone) increases with the increasing $\mathrm{w} / \mathrm{c}$ in the range 0.25 to 0.50 , with a negligible effect on hydration for $w / c 0.25$. This may explain why the positive effect on hydration and compressive strength was less visible for the mortar at w/c 0.30 than for that at w/c 0.35. In the former, the interparticle distances of the binder (cement and limestone) were already very low and could not be significantly improved by C-S-H seeding (beyond the initial acceleration reflected by higher strength at $6 \mathrm{~h}$ ). In addition, the mortars at lower w/c had higher superplasticizer dosage, which led to retardation of hydration and hence counteracted the acceleration due to seeding.

\subsection{Effect of seeding on RH and autogenous shrinkage}

A clear effect of seeding on increasing the rates of self-desiccation (Fig. 6) and, consequently, of autogenous shrinkage (Fig. 7) was observed. This was due to faster hydration and finer porosity in the initial $2 \mathrm{~d}$ of hydration. After this time, the rates of self-desiccation and autogenous shrinkage in the mortars with seeding become lower than in the corresponding reference mortars.

The increased rates of autogenous shrinkage may lead to higher risk of early-age cracking [42, 43]. Internal curing with SAP appears to be an efficient method for reducing this negative effect of acceleration. 
An important aspect of internal curing that needs to be considered, especially in the mix design and in assessing the effects of internal curing, regards the absorption potential of the pore fluid by the SAP. It has been suggested in [20] that the SAP absorb less water in the actual cement pastes compared to free absorption, see also [25, 44]. In our mix design, two different dosages of SAP were used for the same w/c of 0.35 . This means that in the mix with more SAP, more pore fluid is absorbed and the basic w/c of the matrix (i.e. excluding the water absorbed by the SAP) is lower. The results presented in the Appendix suggests that the SAP in the mortar absorbed less than determined in the free absorption (tea-bag) tests. It should be however noted that the absorption determined in the tomography is prone to the limitations and artifacts of the image processing. Nevertheless, the more efficient reduction of autogenous shrinkage at the increased SAP dosage $(0.22 \%$ instead of $0.14 \%$ by mass of cement) suggests that the real absorption in the mortar was in fact lower than $35 \mathrm{~g} / \mathrm{g}$, and hence more SAP was necessary to use fully their internal curing potential.

\section{Conclusions}

C-S-H seeding in mortars with w/c of 0.30 and 0.35 led to faster hydration and consequently finer pore structure in the first days of hydration. This corresponded to higher mechanical properties at very early ages (up to about $1 \mathrm{~d}$ ). At later ages (after 2 to $3 \mathrm{~d}$ ) the differences in porosity and also in strength between the reference mortar and the mortar with seeding were not significant at w/c 0.35 .

On the contrary, for lower $w / c$ of 0.30 , seeding resulted in a reduction of strength after $1 \mathrm{~d}$. This might be due to negligible effect of seeding on the interparticle distances in the particular mix with low w/c, while the finer microstructure possibly reduced hydration rates at later ages. In fact, the 
interparticle distances in the presence of the limestone filler are already very small even without seeding. Another explanation of the low strength could be the high autogenous shrinkage rates that may have led to microcracking due to aggregate restraint. These results confirm that $\mathrm{C}-\mathrm{S}-\mathrm{H}$ seeding becomes especially efficient at higher w/c where fast hardening is required. Hence, for using C-S$\mathrm{H}$ seeding also at low w/c ratios like w/c $<0.3$, further studies should focus on adapting the mortar formulation to reduce shrinkage and improve strength.

C-S-H seeding and the corresponding refinement of the microstructure also led to faster selfdesiccation and ultimately lower internal RH in the mortars at both tested w/c. This in consequence led to faster rates and higher magnitude of autogenous shrinkage. This negative effect could be limited by applying internal curing with SAP. Moreover, the combination of C-S-H seeding with SAP allowed to reach even higher strength at early age (at $1 \mathrm{~d}$ ) compared to the mortar with only seeding at the same total $\mathrm{w} / \mathrm{c}$. The acceleration due to C-S-H seeding was still evident (even if at a reduced extent) in mortars where superplasticizer amount was increased considerably to compensate the loss of workability caused by SAP.

The accelerating action of the C-S-H seeding, together with the autogenous shrinkage-reducing effect of SAP can be very beneficial in mortars where fast hardening and reduced shrinkage is necessary, e.g. in repair mortars, grouts or mortars for floor applications. Further studies will focus on the performance of the mortars with C-S-H and SAP during early-age drying (plastic shrinkage). 


\section{Acknowledgements}

We thank Dr Michele Griffa from Empa for running the X-ray tomography and tomographic data reconstruction.

\section{Conflict of interest}

The study reported in this paper was funded by BASF Construction Additives GmbH, Germany.

The C-S-H seeding agent and the SAP were produced by BASF Construction Additives GmbH, Germany.

\section{References}

[1] J. Péra, J. Ambroise, New applications of calcium sulfoaluminate cement, Cem Concr Res 34(4) (2004) 671-676.

[2] W. Shuxin, C.L. Victor, High-Early-Strength Engineered Cementitious Composites, Materials Journal 103(2) (2006) 97-105.

[3] S. Perret, K.H. Khayat, E. Gagnon, J. Rhazi, Repair of 130-Year Old Masonry Bridge using HighPerformance Cement Grout, Journal of Bridge Engineering 7(1) (2002) 31-38.

[4] D.P. Bentz, F. Zunino, D. Lootens, Chemical vs. Physical Acceleration of Cement Hydration, Concrete international: design \& construction 38(11) (2016) 37.

[5] H. Justnes, E.C. Nygaard, Technical calcium nitrate as set accelerator for cement at low temperatures, Cem Concr Res 25(8) (1995) 1766-1774.

[6] B.J. Zhan, D.X. Xuan, C.S. Poon, C.J. Shi, Effect of curing parameters on $\mathrm{CO} 2$ curing of concrete blocks containing recycled aggregates, Cem Concr Compos 71 (2016) 122-130.

[7] R.G. Hutchison, J.T. Chang, H.M. Jennings, M.E. Brodwin, Thermal acceleration of Portland cement mortars with microwave energy, Cem Concr Res 21(5) (1991) 795-799.

[8] J.I. Escalante-García, J.H. Sharp, Effect of temperature on the hydration of the main clinker phases in portland cements: part i, neat cements, Cem Concr Res 28(9) (1998) 1245-1257.

[9] F. Deschner, B. Lothenbach, F. Winnefeld, J. Neubauer, Effect of temperature on the hydration of Portland cement blended with siliceous fly ash, Cem Concr Res 52 (2013) 169-181.

[10] S. Aggoun, M. Cheikh-Zouaoui, N. Chikh, R. Duval, Effect of some admixtures on the setting time and strength evolution of cement pastes at early ages, Constr Build Mater 22(2) (2008) 106-110.

[11] L. Gurney, D. Bentz, T. Sato, W. Weiss, Reducing Set Retardation in High-Volume Fly Ash Mixtures with the Use of Limestone, Transportation Research Record: Journal of the Transportation Research Board 2290 (2012) 139-146. 
Accepted version. Published as: M. Wyrzykowski, A. Assmann, C. Hesse, P. Lura, Microstructure development and autogenous shrinkage of mortars with C-S-H seeding and internal curing, Cem Concr Res 129 (2020) 105967. https://doi.org/10.1016/j.cemconres.2019.105967

[12] T. Oey, A. Kumar, J.W. Bullard, N. Neithalath, G. Sant, The filler effect: the influence of filler content and surface area on cementitious reaction rates, Journal of the American Ceramic Society 96(6) (2013) 1978-1990.

[13] E. Berodier, K. Scrivener, Understanding the Filler Effect on the Nucleation and Growth of C-S-H, Journal of the American Ceramic Society 97(12) (2014) 3764-3773.

[14] J.J. Thomas, H.M. Jennings, J.J. Chen, Influence of Nucleation Seeding on the Hydration Mechanisms of Tricalcium Silicate and Cement, J Phys Chem C 113(11) (2009) 4327-4334.

[15] R. Alizadeh, L. Raki, J.M. Makar, J.J. Beaudoin, I. Moudrakovski, Hydration of tricalcium silicate in the presence of synthetic calcium-silicate-hydrate, Journal of Materials Chemistry 19(42) (2009) 7937-7946.

[16] M.H. Hubler, J.J. Thomas, H.M. Jennings, Influence of nucleation seeding on the hydration kinetics and compressive strength of alkali activated slag paste, Cem Concr Res 41(8) (2011) 842-846.

[17] L. Nicoleau, The acceleration of cement hydration by seeding: influence of the cement mineralogy, ZKG international 1 (2013) 40-49.

[18] O.M. Jensen, P.F. Hansen, Autogenous deformation and RH-change in perspective, Cem Concr Res 31(12) (2001) 1859-1865.

[19] P. Lura, O.M. Jensen, K. van Breugel, Autogenous shrinkage in high-performance cement paste: An evaluation of basic mechanisms, Cem Concr Res 33(2) (2003) 223-232.

[20] O.M. Jensen, P.F. Hansen, Water-entrained cement-based materials: I. Principles and theoretical background, Cem Concr Res 31(4) (2001) 647-654.

[21] D.P. Bentz, O.M. Jensen, Mitigation strategies for autogenous shrinkage cracking, Cem Concr Compos 26(6) (2004) 677-685.

[22] J. Kaufmann, R. Loser, A. Leemann, Analysis of cement-bonded materials by multi-cycle mercury intrusion and nitrogen sorption, Journal of Colloid and Interface Science 336(2) (2009) 730-737.

[23] M. Wyrzykowski, Z. Hu, S. Ghourchian, K. Scrivener, P. Lura, Corrugated tube protocol for autogenous shrinkage measurements: review and statistical assessment, Mater Struct 50(1) (2017) 1-14.

[24] ASTM, ASTM C1698-09 Standard test method for autogenous strain of cement paste and mortar, ASTM International, West Conshohocken, PA, 2009.

[25] C. Schröfl, D. Snoeck, V. Mechtcherine, A review of characterisation methods for superabsorbent polymer (SAP) samples to be used in cement-based construction materials: report of the RILEM TC 260RSC, Mater Struct 50(4) (2017) 197.

[26] J. Zhang, G.W. Scherer, Comparison of methods for arresting hydration of cement, Cem Concr Res 41(10) (2011) 1024-1036.

[27] J. Kaufmann, Pore space analysis of cement-based materials by combined Nitrogen sorption - Wood's metal impregnation and multi-cycle mercury intrusion, Cem Concr Compos 32(7) (2010) 514-522.

[28] S. Diamond, Mercury porosimetry: An inappropriate method for the measurement of pore size distributions in cement-based materials, Cem Concr Res 30(10) (2000) 1517-1525.

[29] S. Wild, A discussion of the paper "Mercury porosimetry-an inappropriate method for the measurement of pore size distributions in cement-based materials" by S. Diamond, Cem Concr Res 31(11) (2001) 1653-1654.

[30] A.C.A. Muller, K.L. Scrivener, A reassessment of mercury intrusion porosimetry by comparison with 1H NMR relaxometry, Cem Concr Res 100(Supplement C) (2017) 350-360.

[31] P. Siler, J. Kratky, N. De Belie, Isothermal and solution calorimetry to assess the effect of superplasticizers and mineral admixtures on cement hydration, J Therm Anal Calorim 107(1) (2012) 313320. 
Accepted version. Published as: M. Wyrzykowski, A. Assmann, C. Hesse, P. Lura, Microstructure development and autogenous shrinkage of mortars with C-S-H seeding and internal curing, Cem Concr Res 129 (2020) 105967. https://doi.org/10.1016/i.cemconres.2019.105967

[32] D. Marchon, R.J. Flatt, Chapter 12 - Impact of chemical admixtures on cement hydration, in: P.-C. Aitcin, R.J. Flatt (Eds.), Science and Technology of Concrete Admixtures, Woodhead Publishing 2016, pp. 279-304.

[33] G. Sant, P. Lura, J. Weiss, A discussion of analysis approaches for determining 'time-zero'from chemical shrinkage and autogenous strain measurements in cement paste, in: O. Jensen, P. Lura, K. Kovler (Eds.) International RILEM conference on volume changes of hardening concrete: testing and mitigation, RILEM Publications SARL, 2006, pp. 375-383.

[34] M. Seddik Meddah, A. Tagnit-Hamou, Evaluation of Rate of Deformation for Early-Age Concrete Shrinkage Analysis and Time Zero Determination, J Mater Civ Eng 23(7) (2011) 1076-1086.

[35] M. Wyrzykowski, Z. Hu, S. Ghourchian, K. Scrivener, P. Lura, Corrugated tube protocol for autogenous shrinkage measurements: review and statistical assessment, Mater Struct 50(1) (2016) 57.

[36] I. Pane, W. Hansen, Early age creep and stress relaxation of concrete containing blended cements, Mater Struct 35(2) (2002) 92.

[37] J.J. Thomas, A New Approach to Modeling the Nucleation and Growth Kinetics of Tricalcium Silicate Hydration, Journal of the American Ceramic Society 90(10) (2007) 3282-3288.

[38] J. Justs, M. Wyrzykowski, F. Winnefeld, D. Bajare, P. Lura, Influence of superabsorbent polymers on hydration of cement pastes with low water-to-binder ratio, J Therm Anal Calorim 115(1) (2014) 425-432.

[39] M. Wyrzykowski, P. Lura, Effect of relative humidity decrease due to self-desiccation on the hydration kinetics of cement, Cem Concr Res 85 (2016) 75-81.

[40] A. Idiart, J. Bisschop, A. Caballero, P. Lura, A numerical and experimental study of aggregate-induced shrinkage cracking in cementitious composites, Cem Concr Res 42(2) (2012) 272-281.

[41] V. Bonavetti, H. Donza, G. Menéndez, O. Cabrera, E.F. Irassar, Limestone filler cement in low w/c concrete: A rational use of energy, Cem Concr Res 33(6) (2003) 865-871.

[42] D.P. Bentz, A review of early-age properties of cement-based materials, Cem Concr Res 38(2) (2008) 196-204.

[43] A.M. Paillere, M. Buil, J.J. Serrano, Effect of Fiber Addition on the Autogenous Shrinkage of Silica Fume, Materials Journal 86(2) (1986) 139-144.

[44] J. Justs, M. Wyrzykowski, D. Bajare, P. Lura, Internal curing by superabsorbent polymers in ultra-high performance concrete, Cem Concr Res 76(0) (2015) 82-90.

[45] J. Siramanont, W. Vichit-Vadakan, W. Siriwatwechakul, The impact of SAP structure on the effectiveness of internal curing, International RILEM Conference on Use of Superabsorbent Polymers and Other New Additives in Concrete, RILEM Publications SARL, 2010, pp. 243-252.

[46] O.M. Jensen, P.F. Hansen, Water-entrained cement-based materials II. Experimental observations, Cem Concr Res 32(6) (2002) 973-978.

[47] L.A. Feldkamp, L. Davis, J.W. Kress, Practical cone-beam algorithm, Josa a 1(6) (1984) 612-619.

[48] W.S. Rasband, ImageJ, U. S. National Institutes of Health, Bethesda, Maryland, USA, 1997-2014.

[49] L.P. Esteves, Superabsorbent polymers: On their interaction with water and pore fluid, Cem Concr Compos 33(7) (2011) 717-724.

[50] L.P. Esteves, O.M. Jensen, Absorbency of Superabsorbent Polymers in Cementitious Environments, MRS Proceedings 1488 (2012) imrc12-1488-7b-022.

[51] L.P. Esteves, On the absorption kinetics of superabsorbent polymers, Use of Superabsorbent Polymers and Other New Additives in Concrete, RILEM publications SARL, 2010.

[52] C. Schröfl, V. Mechtcherine, M. Gorges, Relation between the molecular structure and the efficiency of superabsorbent polymers (SAP) as concrete admixture to mitigate autogenous shrinkage, Cem Concr Res 42(6) (2012) 865-873. 
Accepted version. Published as: M. Wyrzykowski, A. Assmann, C. Hesse, P. Lura, Microstructure development and autogenous shrinkage of mortars with C-S-H seeding and internal curing, Cem Concr Res 129 (2020) 105967. https://doi.org/10.1016/j.cemconres.2019.105967

[53] S.-H. Kang, S.-G. Hong, J. Moon, Absorption kinetics of superabsorbent polymers (SAP) in various cement-based solutions, Cem Concr Res 97 (2017) 73-83.

\section{Appendix - Estimation of SAP absorption in the mortars}

The absorption of pore fluid by the SAP was estimated based on the tomographic data first by determining the volume of the SAP-voids in the hydrating mortar and dividing it by the initial volume of the SAP voids (the latter value known from mix composition, assuming the density of SAP of $1.4 \mathrm{~g} / \mathrm{cm}^{3}$ as determined on the same SAP type in a previous study [44]).

Next, the mass absorption can be determined assuming density of the absorbed liquid as equal to the density of water, $1 \mathrm{~g} / \mathrm{cm}^{3}$.

The mortar C-S-H+SAP 0.35 (see Table 1) was mixed in a vacuum mixer (in order to minimize the volume of air voids) and cast in a 10-mm layer in a $\varnothing 10-\mathrm{mm}$ glass cylinder. The X-ray tomographic scans started at $2 \mathrm{~h}$ from mixing and lasted for about $2.5 \mathrm{~h}$. Such early start of the scan allowed avoiding the buildup of hydration products within the original spaces occupied by the swollen SAP. Such phenomenon, reported in e.g. [44-46], could lead to underestimation of the SAP-originated voids and hence underestimation of the SAP absorption X-ray micro-tomography was performed with a cone-beam instrument at Empa's Center for X-ray Analytics. 1441 X-ray radiographs were acquired while rotating the specimen over $360^{\circ}$. The tomographic reconstruction was performed with a standard cone-beam filtered back-projection algorithm [47]. The obtained reconstructed 3-D dataset had voxel size of $6.3 \mu \mathrm{m}$.

All the voids were fist segmented by means of simple operator-aided thresholding. The 3-D rendering of the voids is presented in Fig. A1. Next, the touching particles were separated using a 3-D watershed split algorithm available in the ImageJ software [48]. Finally, the spherical air voids 
and the irregular-shaped SAP-voids were separated based on their shape metrics. The shape metrics used for this purpose was the ratio between the dimensions of a binding box enclosing a single void. The ratio between the smallest and the largest dimension is equal to 1 for a perfectly spherical object and approaches zero for objects with infinite aspect ratios. Based on visual inspection, particles with ratio above 0.9 were considered spherical and classified as air voids. In Fig. A2 an exemplary horizontal section is presented in which SAP-voids and air voids are identified.

The found volumes of the air voids and SAP-voids were: 1.1 and $1.3 \%$, respectively. The found volume of SAP-voids corresponds to an absorption potential of only $12 \mathrm{~g} / \mathrm{g}$. The fact that the volume of SAP-voids found with X-ray microtomography is considerably smaller than found with the free absorption tests suggests that only part of the voids could be resolved with X-rays due to too low contrast or too low resolution (see Fig. A2).

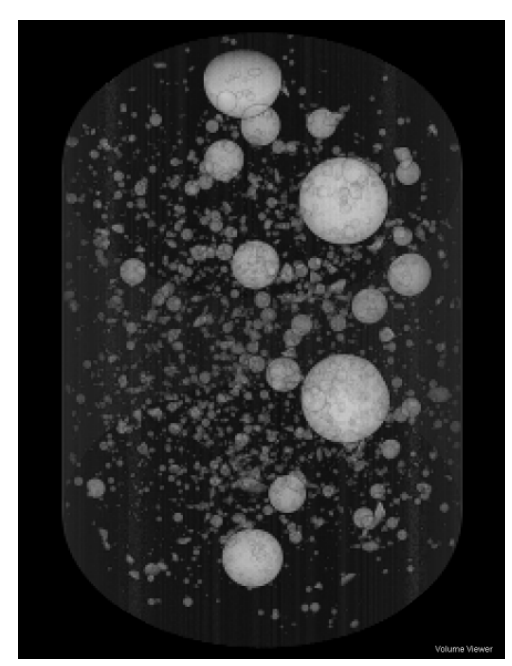

Fig. A1. 3-D rendering of the voids (air voids $+S A P$-voids) in the $C-S-H+S A P 0.35$ mortar. The cylindrical sample had 10-mm diameter and about 10-mm height. 

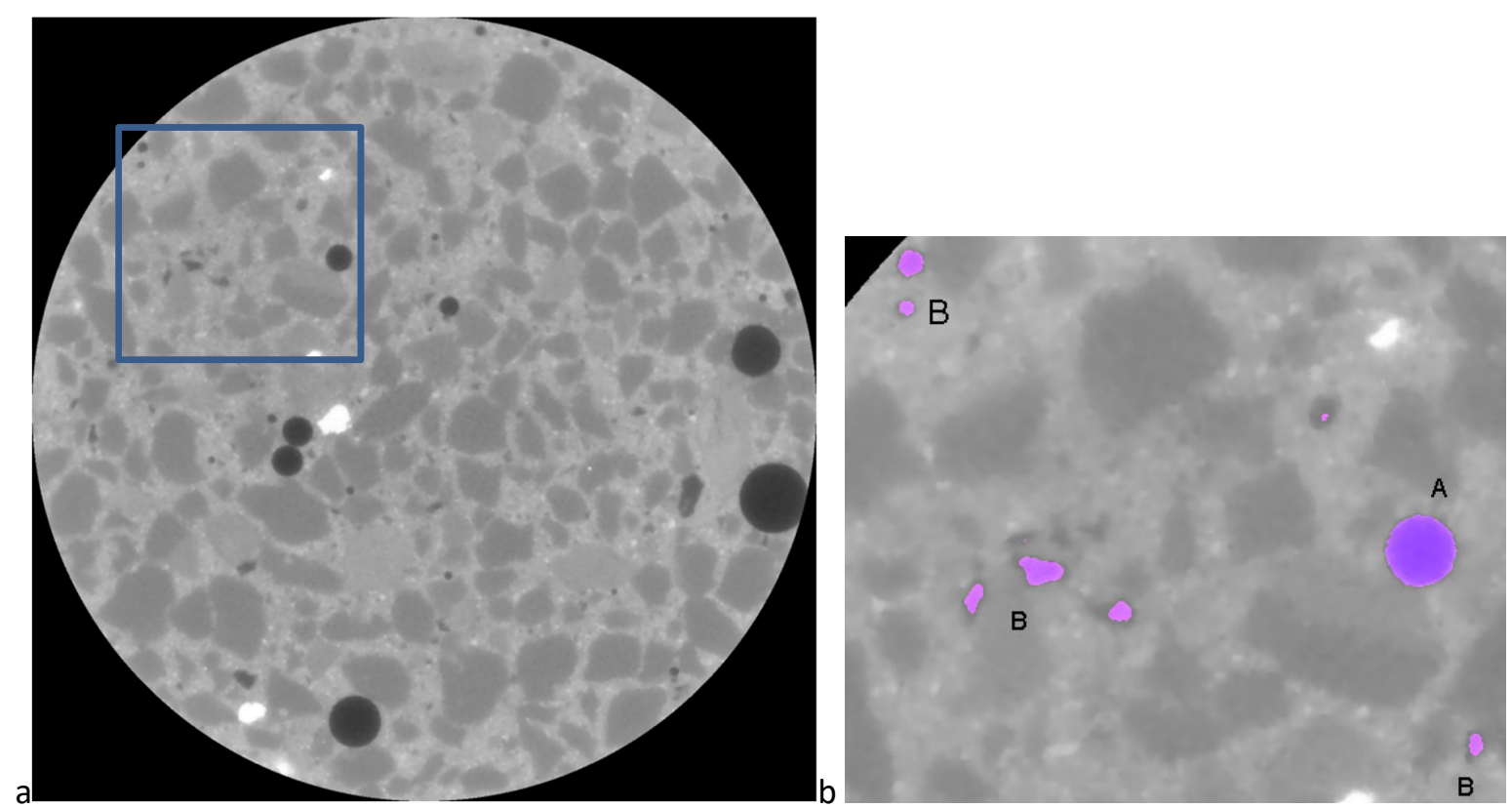

Fig. A2. a) Horizontal section through the reconstructed $X$-ray tomography dataset (C-S-H+SAP 0.35 mortar). b) magnified area indicated by a frame. The following features can be seen in the insert: $A$ - air voids, $B$-SAP-voids.

Therefore, another method was used based on the size distribution of the resolved SAP-voids and next comparing it to the particle size distribution of the dry SAP (determined with laser diffraction). In this way, by comparing the change in sizes, one can estimate the corresponding changes in volume between dry and wet SAP, hence their volumetric absorption.

In Fig. A3, the cumulative size distributions of particles/voids are presented. In the size calculations, sizes of SAP-voids refer to diameters of the equivalent spherical voids (i.e. diameter of a sphere that has equal volume as the corresponding, non-spherical SAP-void). After assuming that all SAP particles, independent of their sizes, increase their size equally upon pore fluid water absorption (in other words, that the absorption by volume or mass is independent of the size of the 
SAP), it is estimated that the dry particles expand by about a factor 2.85 in order to produce a size distribution agreeing with that of swollen SAP-particles as resolved from the tomographic data, Fig. A2. The $2.85 \times$ increase in size corresponds to the volumetric absorption of about $22 \mathrm{~cm}^{3} / \mathrm{cm}^{3}$, which for the SAP density of $1.4 \mathrm{~g} / \mathrm{cm}^{3}$ further corresponds to the mass absorption of $16 \mathrm{~g} / \mathrm{g}$. It should be stressed that the size estimations are sensitive to the separation algorithm that is employed (here, a 3-D watershed split). When the particles are not detached with the 3-D watershed split algorithm, the increase of size becomes $3.55 \times$, which corresponds to $31 \mathrm{~g} / \mathrm{g}$ absorption.

It should be also noted that assuming the same expansion for all particles, independent of their size, is a simplification. It should be noted that the estimation based on a single size shift factor between the dry and swollen particles presented here may be prone to errors if the particles swell differently for different grain sizes.

According to Jensen and Hansen [46], larger particles may absorb relatively less water than the small particles due to insufficient time for absorption during mixing.

On the other hand, water absorption of the smaller particles may be reduced due to less active surface zone compared to the bulk [46]. These considerations are in line with the experimental data by Esteves [49], who reported that larger SAP particles experience slower, but ultimately higher absorption while swelling freely in water or synthetic pore fluid. On the other hand, a maximum absorption was found in [50]for particles in the size ranges $75-150 \mu \mathrm{m}$, and lower absorption for smaller and larger particles.

Other factors, like surface area of the SAP, intrinsic absorption kinetics, or breaking of larger particles during mixing may also play a role and consequently lead to incorrect estimations of the absorption [51-53]. 


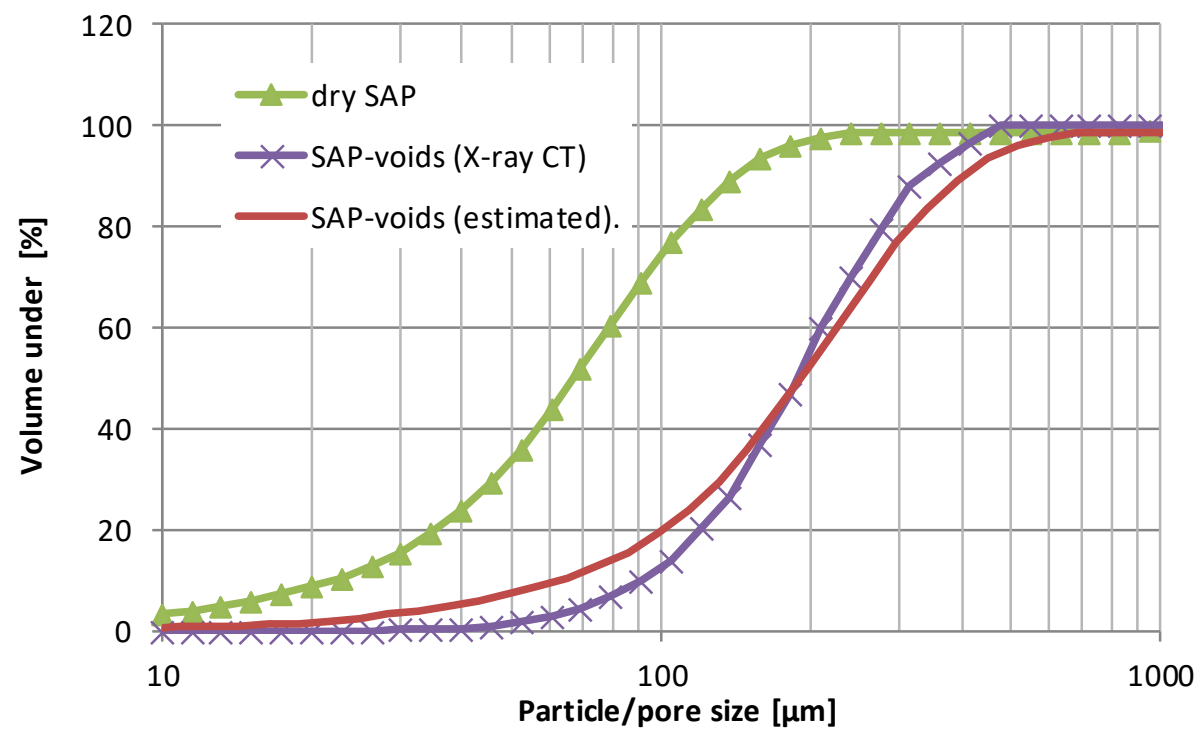

Fig. A3. Size distribution of dry SAP particles and SAP-voids and the estimated curve obtained by multiplying the sizes of dry particles $2.85 \times$ (corresponding to the absorption constant for all particles equal to $16 \mathrm{~g} / \mathrm{g})$. 